\title{
SUPUESTOS CONFLICTOS DE DERECHOS HUMANOS Y LA ESPECIFICACIÓN DE LA ACCIÓN MORAL*
}

\author{
SUPPOSED CONFLICTS OF HUMAN RIGHTS AND THE \\ SPECIFICATION OF MORAL ACTION
}

\section{CRISTÓBAL ORREGo SÁNCHEZ**}

\begin{abstract}
RESUMEN: El autor critica el razonamiento jurídico que se basa en los llamados "conflictos de derechos humanos". En su lugar sugiere razonar prácticamente basándose en la identificación de especies de actos.
\end{abstract}

Palabras claves: derechos, conflictos, razonamiento, especificación.

ABSTRACT: The author criticises legal reasoning that is based on so-called "conflicts of human rights". He suggests, instead, to reason practically on the basis of the identification of species of acts.

Key words: rights, conflicts, reasoning, specification.

\section{PLANTEAMIENTO}

En el marco de una investigación sobre el razonamiento práctico (ético, jurídico y político) y la especificación del acto moral, se advierte el uso corriente de la categoría del derecho subjetivo y del planteamiento de los casos judiciales sobre derechos fundamentales como casos de conflictos de derechos (o entre derechos y otros bienes) o de aparentes conflictos de derechos o de conflictos entre pretensiones jurídicas. En estos modos de plantear las controversias, se ha perdido de vista el lugar central que ocupa, en la filosofía de la acción (antigua, moderna y contemporánea, de diversas orientaciones filosóficas), el problema de la especificación del acto moral. Se sugiere que esta situación de pobreza argumental es inconveniente, y que puede subsanarse mediante la recuperación del razonamiento práctico que considera como centrales los tipos de acciones y su adecuada descripción.

Un primer indicio a favor de esta sugerencia estriba en que la categoría de los derechos subjetivos no es primaria, ni de ninguna manera central, en el pensamiento jurídico de los principales autores clásicos y contemporáneos. Coinciden en este punto

\footnotetext{
* Este artículo es resultado de una investigación en curso sobre la relevancia de la especificación de la acción moral para el razonamiento práctico ético y jurídico, patrocinado por el Fondo Nacional de Ciencia y Tecnología. Proyecto Fondecyt 1080680.

${ }_{* *}^{*}$ Licenciado en Derecho por la Pontificia Universidad Católica de Chile. Abogado. Máster en Artes Liberales y Doctor en Derecho por la Universidad de Navarra. Profesor de Filosofía del Derecho en la Universidad de los Andes (Chile). Av. San Carlos de Apoquindo 2200, Las Condes, Santiago. Correo electrónico: corrego@uandes.cl. Teléfono: 4129456.
} 
-esto es, en rechazar los derechos subjetivos como categoría primaria de pensamiento jurídico- autores tan disímiles como Hans Kelsen ${ }^{1}$ y Michel Villey ${ }^{2}$. Massini resume esta posición transversal entre iusnaturalistas y iuspositivistas cuando afirma que el derecho subjetivo "se sigue como consecuencia (...) de la calidad de debida u obligatoria de una conducta jurídica" 3 , por lo que "no es fundamento o realidad primera sino que se explica

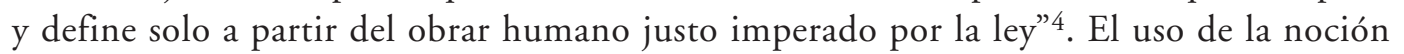
de derecho subjetivo se comienza a extender a partir de Europa, en el siglo XVI, aunque el sentido subjetivo del ius ya era prominente en Occam, y estaba implícito, aunque secundariamente, en algunas fuentes del derecho canónico y del derecho romano precedente $^{5}$. En el caso de los derechos subjetivos más altos (i.e., los derechos naturales o humanos), su lugar subordinado en la argumentación jurídica y en el razonamiento práctico en general resultaba patente porque su aplicación requería siempre de leyes que establecieran sus contornos más definidos y que configuraran las respectivas obligaciones. Esta situación comienza a cambiar cuando los tribunales supremos o constitucionales $\mathrm{y}$, en algunas jurisdicciones, incluso todos los tribunales ordinarios, comienzan a aplicar directamente la Constitución o los derechos fundamentales. Entonces la apelación a los derechos humanos comienza a servir para dejar sin efecto normas imperativas o prohibitivas específicas, esto es, para cancelar obligaciones definidas mediante la apelación a derechos abstractos. El fenómeno ha sido explosivo y ha operado en dos direcciones. Por una parte, ha convertido la Constitución escrita en norma directamente aplica$\mathrm{da}$ en concurrencia con las leyes ordinarias, y, por ende, en un instrumento para anularlas - la norma inconstitucional no vale, ya en general, ya en el caso- o para darles una interpretación acorde con la visión constitucional -política- de los jueces. Así se habla de la juridificación de la Constitución, pues la Norma Suprema constituye derecho aplicable por sí mismo, sin necesidad de la mediación de leyes aplicadoras. Por otra parte, como otra cara de la misma moneda, las mismas normas subconstitucionales y todas las áreas del derecho, que antes existían con relativa autonomía dentro del marco político provisto por la Constitución, han comenzado a configurarse mediante normas de creación doctrinal o jurisprudencial basadas en los principios, valores y normas de jerarquía constitucional, entre los cuales sobresalen los derechos esenciales reconocidos o garantizados por los textos constitucionales. Así se habla de la constitucionalización del derecho $^{6}$.

Esta evolución multifacética equivale, desde el punto de vista político-institucional, a una traslación de las potestades creadoras del derecho desde los representantes elegidos (Congreso Nacional) hacia los jueces y los juristas doctrinarios (judicatura y academia).

\footnotetext{
${ }^{1}$ KeLSEN (1969) pp. 87-108; KelSEN (1994) pp. 142-143.

2 Villey (1976a), Villey (1976b) y GUZMÁN BRITO (1976).

${ }^{3}$ MASSINI CORREAS (1987) p. 65.

${ }^{4}$ Massini Correas (1987) p. 65. Una síntesis de la cuestión en SALDAÑa (2000).

5 Villey (1976), Tierney (1997), y, más actualizadamente, Megías (2003).

${ }^{6}$ El fenómeno ha sido descrito adecuadamente -con especial referencia a sus inicios en el derecho constitucional alemán- por CRUZ (2005).
} 
Este cambio de paradigma ha convertido la apelación a los derechos humanos en un elemento central de la argumentación jurídica y, al menos en el nivel de las apariencias, del razonamiento práctico jurídico acerca de qué debe darse o adjudicarse a cada parte en una controversia. La argumentación iusfundamentalista consiste en insertar la apelación a una determinada comprensión de los derechos humanos dentro del proceso práctico de razonamiento que ha de llevar a una determinada conclusión práctica, es decir, acerca de qué se debe hacer o de cómo se debe decidir un caso. La existencia y la eficacia de la argumentación iusfundamentalista están fuera de dudas. Más dudoso es, en cambio, que un razonamiento jurídico válido y justificatorio de una decisión acerca de los derechos de las personas pueda fundarse realmente en esa argumentación edificada sobre la apelación a un derecho fundamental y su supuesta prelación respecto de otro u otros.

En este artículo sostendré que la argumentación iusfundamentalista conduce a contraponer los derechos naturales (o humanos, fundamentales) como si entre ellos hubiera un conflicto, real o aparente, que ha de resolverse a favor de un derecho o del otro. Las reivindicaciones opuestas y el razonamiento práctico que pretende mantenerse en el nivel del conflicto de derechos olvidan, sin embargo, los clásicos modos de razonar en términos de acciones debidas. Este modo clásico de razonar exige identificar no tanto derechos cuanto especies de actos humanos. No se excluye la identificación de derechos en cuanto bienes atribuidos a otro según una medida específica, porque determinadas acciones debidas pueden depender, para su adecuada descripción intencional, de alguna asignación de derechos. Sin embargo, lo prioritario para el razonamiento práctico es la identificación de las acciones según sus especies, porque solamente las acciones son susceptibles de consideración como debidas o indebidas en el marco del silogismo práctico.

La tesis que propongo es que, por no razonar en términos de acciones debidas, los casos descritos como conflictos entre derechos humanos se resuelven de manera intuitiva, y, aunque puedan ser resueltos correctamente - pues la intuición del juez prudente opera, como el phrónimos aristotélico, identificando la acción debida-, en realidad se buscan a posteriori las racionalizaciones aceptables en términos de derechos humanos. Este modo de proceder aboca indefectiblemente a la arbitrariedad judicial, por lo menos, si no en la determinación misma de la respuesta correcta, sí en el proceso de justificación posterior. Es menester, por ende, volver a modos de razonamiento práctico jurídico centrados en la formulación de principios y de normas (o reglas) que describan adecuadamente diversos tipos de acciones y que proporcionen las razones de por qué pueden ser obligatorias, prohibidas o lícitas, y bajo qué circunstancias relevantes. Los derechos humanos no pueden funcionar como categoría conceptual de razonamiento, sino solamente como categoría conceptual para expresar abstractamente algunos deberes de justicia -al señalar sus objetos en general- y para enunciar concretamente, aunque no del modo más preciso, algunas conclusiones del razonamiento práctico ético y jurídico sobre el mejor modo de proteger y de respetar a las personas, que son los titulares de esos derechos.

Procederé en seis etapas. Primero expondré someramente en qué consiste el razonamiento práctico jurídico. Después presentaré el contexto de la dogmática constitucional chilena, que puede servir para comprender el interés de mis sugerencias desde la filosofía del derecho, aunque -forzoso es advertirlo- este artículo no constituye un 
aporte desde la dogmática jurídica, ni pretende operar con sus presupuestos, sino que es, sobre todo, una reflexión crítica iusfilosófica externa a la dogmática misma. En seguida, me referiré a la argumentación iusfundamentalista, que se expresa en términos de conflictos de derechos. En cuarto lugar, me referiré esquemáticamente a los intentos de solucionar los conflictos de derechos mediante razonamientos que se centran en los derechos mismos, especialmente mediante su jerarquización, su ponderación o su limitación por criterios externos. En este caso, se presentan esos métodos como los más usuales en el derecho comparado, pero nuevamente debo advertir que este artículo no tiene como objetivo exponer el detalle de esas posturas tal como se desarrollan en la dogmática constitucional y en la jurisprudencia, sobre lo cual nos remitimos a obras especializadas. En quinto lugar, mostraré que ese modo de razonar lleva a un callejón sin salida; aboca a lo que considero una combinación inaceptable de arbitrariedad en la decisión e hipocresía en la justificación. Obviamente, defiendo aquí una postura valorativa que oriente la correcta interpretación y aplicación del derecho, como es propio de un análisis filosófico-jurídico sin pretensiones de neutralidad axiológica. Mi opinión es que la lógica del análisis se complementa con la justicia de una hermenéutica constitucional centrada en clases de actos, que no oculta las verdaderas motivaciones y justificaciones de las sentencias. Por último, fundándome en la filosofía de la acción y, especialmente, en algunas tesis sobre la especificación de la acción, haré una propuesta positiva de razonamiento práctico que, admitiendo la necesidad de especificar o concretar los derechos fundamentales, ya no se base en la consideración de los derechos en juego (o supuestamente en conflicto), sino en una reflexión sobre los tipos de acciones prohibidas, debidas o permitidas.

\section{LA ESTRUCTURA DEL RAZONAMIENTO PRÁCTICO JURÍDICO}

El razonamiento práctico jurídico es un caso especial del razonamiento práctico general, el cual, a su vez, se entiende en el marco de la explicación sobre la tercera operación de la razón, que es el raciocinio. El raciocinio es un acto de la razón humana, posterior a la formación de los conceptos y a la enunciación de proposiciones significativas, que articula dos o más proposiciones para arribar a una tercera ${ }^{7}$. El sentido de todo razonamiento es progresar en el conocimiento, yendo desde lo conocido a lo desconocido. El punto de partida siempre está en la experiencia sensible, a partir de la cual formamos nociones básicas y juicios primeros. Los primeros principios per se nota (i. e., conocidos por todos como verdaderos), como el principio de contradicción, son usados implícitamente en toda forma de raciocinio, tanto teórico como práctico. El progreso en el conocimiento, ya sea por experiencia propia, ya por información recibida, supone añadir conceptos y proposiciones nuevas, así como los hábitos que permiten retener y avanzar en la ciencia. Mediante los procedimientos propios de cada ciencia, que combinan formas de deducción -razonamiento deductivo más o menos abstracto-, inducción -generalizaciones más o menos seguras, que podrían ser estrictamente universales, a 
partir de la observación de casos particulares- y otros procedimientos como la abducción -generar una hipótesis que podría explicar un fenómeno, para luego someterla a examen-, y mediante las formas sociales de transmisión de esos conocimientos, se descubren y se propagan los conocimientos descriptivos del mundo ${ }^{8}$.

El razonamiento práctico, en cambio, no tiene por objeto aquello que es, sino aquello que se obra. La razón práctica no es una facultad diversa, sino el uso práctico de una única facultad. Llamamos razón práctica a la misma razón humana cuando dirige los conocimientos que posee hacia hacer algo. "El razonamiento práctico es el razonamiento dirigido a la acción: hallar qué hacer, en cuanto contrastado con hallar cómo se presentan los hechos"'. Su objeto está definido por la pregunta "¿qué he de hacer?”. Por eso, porque dirige la acción, aunque utiliza premisas teóricas (v.gr., información sobre la materia con que se relaciona la acción, como el agua o una piedra) y premisas teóricoprácticas $(v . g r$., proposiciones generales acerca de la acción y del deber, como que se debe respetar al prójimo), el razonamiento práctico termina siempre en la acción misma (salvo impedimento contra la voluntad del agente) y en la proposición en gerundivo que describe la acción (hoc est faciendum: se ha de hacer esto, donde "esto" es la descripción inmediata de la acción intencional).

El modelo clásico de razonamiento práctico es el silogismo práctico que describió Aristóteles, y que ha sido revitalizado notablemente en el ámbito de la filosofía analítica de la acción por autores como G. H. von Wright, E. Anscombe, D. Davidson y otros ${ }^{10}$. Un silogismo práctico tiene una premisa mayor, que es la proposición que remite intencionalmente al fin deseado - puesta, por tanto, por el deseo, ya sea racional o subracional-; una premisa menor, que es la proposición que remite intencionalmente a los medios conocidos como posibles aquí y ahora - puesta, por tanto, por el conocimiento-; y una conclusión, que, si no hay impedimentos, es la acción misma que se sigue necesariamente $^{11}$ (por cierta analogía, también podría decirse que la conclusión es la proposición imperativa inmediatamente precedente a la elección que configura la acción ${ }^{12}$ ).

Sin embargo, si uno quisiera describir un razonamiento práctico más completamente -esto es, más allá de un silogismo sencillo inmediatamente precedente a una acción-, podría añadir que el razonamiento práctico presupone por lo menos lo siguiente: (i) Todos los conocimientos teóricos relevantes para el contexto de acción (metafísi-

\footnotetext{
${ }^{8}$ En lógica y filosofía de la ciencia se discute sobre la deducción -que parece solamente explicitar conocimientos- y sobre la inducción -que enfrenta el problema de pasar de lo particular a lo estrictamente universal, posibilidad criticada o rechazada desde David Hume en adelante-, y, desde Charles S. Pierce, también sobre la abducción, que en filosofía del derecho ha sido tenida en cuenta por Arthur Kaufmann. Véase Jolivet (1960) pp. 92 ss. y KAUfMANn (1999) pp. 148 ss. y la bibliografía ahí citada.

${ }^{9}$ Millgram (2001) p. 1.

10 Vigo (2006a) p. 288.

${ }^{11}$ La síntesis de esta interpretación del silogismo práctico se toma de ViGo (2006a), VigO (2006b), ViGO (2006c), Vigo (2006d) y Vigo (2007) pp. 185-190.

12 En este punto me aparto de lo que Vigo afirma, para acercarme a la tesis de Tomás de Aquino, según el cual la conclusión del silogismo práctico es el juicio mismo de la razón, al cual sigue la elección y finalmente la acción elegida. Véase $S$. th. I-II, q. 13, a. 1, ad 2, y a. 2. Sobre la posición de Tomás de Aquino, sigo la explicación de Miranda (2006) p. 238.
} 
cos, científicos, de experiencia directa, etc.), donde se incluyen los primeros principios especulativos; (ii) los primeros principios prácticos per se nota, como que el bien se ha de hacer y proseguir y el mal se ha de evitar y algunos juicios generales que identifican algunos bienes humanos básicos como vivir, conocer, tener amigos, etc.; (iii) todas las otras verdades, principios y reglas prácticas derivadas, que tradicionalmente se denominaban los preceptos secundarios y terciarios de la ley natural (y que hoy suelen denominarse de diversos modos según el contexto filosófico: principios éticos, exigencias básicas de la justicia, valores morales...), y que incluyen incluso las normas convencionales de diversos tipos en la medida en que algún principio práctico las haga moralmente vinculantes (aquí incluimos las leyes, costumbres, etc.); y, finalmente, (iv) los deseos y los conocimientos inmediatos que, presuponiendo ese plexo de precedentes implícitos (números (i) al (iii)), concurren en la producción de la decisión/acción contingente.

Tal es el marco general del razonamiento práctico, que termina siempre simultáneamente en una decisión/acción y en la sentencia o juicio de elección correspondiente (i.e., en una acción descrita tal como se presenta en el último juicio práctico que se corresponde con la elección del acto). La correlación entre la elección del acto y el último juicio práctico sobre el acto consiste en que este es determinado como juicio por el acto intelectual que constituye su contenido proposicional -formulable en gerundivo- y es determinado como último por un acto desiderativo racional, que es la elección misma, mientras que esta es determinada en su contenido intencional proposicional por el juicio práctico precedente, pero consiste en un acto volitivo o desiderativo racional de autodeterminación respecto de ese contenido preciso. La autodeterminación exige, no obstante, todo el proceso precedente de motivación (desiderativa-racional) y de representación (racional) del acto con vistas al fin ${ }^{13}$.

En este contexto se entiende que el razonamiento jurídico y la argumentación jurídica constituyen un caso especial del razonamiento/argumentación práctica general, en el sentido en que Alexy afirma -en el marco de su pensamiento inspirado en la ética discursiva de Habermas- que "el discurso jurídico es un caso especial del discurso práctico general" 14 . Alexy adopta una forma especial de esta tesis, que él denomina "tesis de la integración", según la cual "el uso de argumentos específicamente jurídicos debe unirse, en todos los niveles, con el de los argumentos prácticos generales" ${ }^{15}$. En el último apartado veremos que esta tesis está implícita en la propuesta de reintegrar el razonamiento práctico-jurídico al tronco de la filosofía de la acción y del silogismo práctico. Ahora debemos destacar, no obstante, la otra cara de la moneda, esto es, que los principios racionales generales y la argumentación moral general no son suficientes para resolver controversias jurídicas. "Debido a su alto grado de generalidad, estas proposiciones no son utilizables directamente para fundamentar una decisión. Se necesitan premisas normativas adicionales" ${ }^{\prime 6}$. Además, existen restricciones históricas e institucio-

13 S. th. I-II, qq. 6-17; FinNis (1998) pp. 62-71 y 96; VigO (2006a) pp. 291-296 y Vigo (2006b) pp. 305-309.

${ }^{14}$ Alexy (1997) p. 34.

15 AleXY (1997) p. 39; véase pp. 38-39.

16 AleXY (1997) p. 234, nota 81. 
nales que varían de jurisdicción en jurisdicción ( v.gr., reglas probatorias, garantías procesales, vigencia de los precedentes, etc. $)^{17}$. Por eso, razonar prácticamente en el ámbito jurídico es dirigir el razonamiento hacia la finalidad práctica de hacer justicia conforme al derecho, y no simplemente alcanzar la solución más justa posible simpliciter ${ }^{18}$. Todas las diferencias específicas, no obstante, aunque explican ese relativo aislamiento del razonamiento jurídico respecto del flujo general del razonamiento práctico moral ${ }^{19}$, no eliminan los rasgos comunes de su género que es el razonamiento práctico.

El razonamiento práctico jurídico (y la argumentación jurídica, que proporciona razones para orientar ese razonamiento) mantiene la estructura esencial del razonamiento práctico general: se ordena a un bien como fin, puesto por el deseo (racional); discierne de entre los medios posibles, es decir, examina -con los argumentos disponibles- las alternativas de sentencia que más se ajustan al fin deseado, que es hacer justicia conforme al derecho -dar a cada uno lo suyo-; y, finalmente, tras excluir las alternativas imposibles (i.e., con Alexy: "discursivamente imposibles" ${ }^{20}$ ), selecciona una de las alternativas posibles (una de las sentencias justas, cuando no hay una sola respuesta correcta) y dictamina conforme a ella. La especificidad del razonamiento práctico jurídico viene dada por su objeto, que es el ius o lo suyo de cada uno; por su finalidad, que es dar a cada uno lo suyo; y por los medios y formas determinadas en que lo suyo de cada uno se concreta como algo que se ha de dar o de respetar a alguien. Este objeto -reitero- no es lo justo ideal, lo que sería más justo en circunstancias ideales y con conocimiento perfecto por parte del juzgador, sino lo justo concreto como objeto técnicamente delimitado por el orden jurídico positivo, que vincula a los jueces para sentenciar en cada caso $^{21}$. Sin embargo, si el orden jurídico vigente estableciera restricciones excesivas a la determinación de lo justo por los ciudadanos, abogados y jueces, es decir, si las normas positivas fueran excesivamente injustas, ese relativo aislamiento del razonamiento técnico-jurídico respecto del flujo general de la razón práctica moral se tornaría problemático o derrotable: se justificaría retroalimentar el razonamiento práctico jurídico con los principios generales justificadores de interpretaciones rectificadoras (epiqueya) o derechamente de desobediencia a las leyes expresas mediante sentencias contra legem ${ }^{22}$.

El juez es el paradigma de razonamiento jurídico. Los demás agentes (ciudadanos, abogados) argumentan apelando al juez, de manera que la argumentación jurídica se configura como un ofrecimiento de razones que podrían jugar un rol en el razonamiento práctico completo, que es el del juez. A su vez, los jueces se ven obligados a argumentar sus sentencias mostrando las razones que han tenido para decidir, pero no apelando ya a la decisión de otros, sino, a lo más, a su aprobación (especialmente en sistemas democráticos, donde, según la ideología democrática, la autoridad del juez es legítima por una

\footnotetext{
${ }^{17}$ AleXy (1997) pp. 205-206, 223, 274-275.

18 AleXy (1997) pp. 274-275.

${ }^{19}$ FinNis (1980) pp. 314-320 y 345.

20 AleXy (1997) pp. 37, 137 ss. y 201-202.

${ }^{21}$ HeRVAdA (1993a) pp. 36-39 y 111-114.

22 Así lo sostienen autores tan dispares como HerVADA (1993a) pp. 111-114 y 187-188, y HART (1961) pp. 205-206.
} 
delegación de la comunidad y por el consentimiento de los gobernados). Los ciudadanos que razonan para sí mismos o en un diálogo o disputa privada con otros ciudadanos lo hacen ad imaginem iudicis. De manera que, en todos los casos, el razonamiento jurídico apunta como su término a una sentencia sobre lo que se ha de hacer para dar o respetar a cada uno lo suyo, con arreglo a los principios de la justicia y a las reglas e instituciones especiales del sistema jurídico.

En suma, la estructura del razonamiento práctico jurídico, si se lo entiende como especie del razonamiento práctico general, necesariamente ha de tener la estructura de una correlación entre el fin puesto por el deseo, el medio discernido por la inteligencia, y la sentencia que dictamina la adopción de ese medio. En esta estructura, el fin deseado no es otro que hacer justicia conforme al derecho. El juez no delibera acerca de este fin, que viene puesto y protegido por el sistema político-institucional. El juez está vinculado al fin, como la razón deliberante del hombre está vinculada al fin puesto por el deseo (en el orden práctico moral, se trata de un deseo racional, es decir, de un fin de la voluntad que ella misma no se da, sino que, a su vez, recibe de un conocimiento primero de los bienes humanos básicos ${ }^{23}$ ). El juez delibera solamente acerca de la premisa menor del silogismo práctico, es decir, considera los argumentos a favor y en contra de considerar determinadas acciones como debidas por alguien a otros. Finalmente, la conclusión de todo razonamiento práctico jurídico -conclusión a las que tienden los argumentos usados en la parte deliberativa del razonamiento- es una sentencia simul indicans et imperans: un juicio práctico que simultáneamente indica un acto debido e impera su realización: restituir una cosa, pagar un precio, indemnizar un perjuicio, infligir una pena, invalidar un contrato, cesar una conducta antijurídica, y así sucesivamente.

\section{LA DOGMÁTICA CONSTITUCIONAL CHILENA ANTE LOS REALES O SUPUESTOS CONFLICTOS ENTRE DERECHOS HUMANOS}

La reflexión iusfilosófica que propongo supone como marco de referencia la discusión sobre los conflictos entre derechos humanos que se ha dado en la dogmática constitucional y, en el nivel de aplicación, en la jurisprudencia constitucional. Actualmente, gracias a la cada vez más rica apertura de la dogmática constitucional chilena al derecho comparado, podemos decir que, si sumamos el conjunto de los autores chilenos, cada uno con su propia orientación científica e ideológica, cabe sostener que a través de ellos puede accederse a las principales orientaciones dogmáticas en otros lugares. En atención a la gran cantidad de autores nacionales que han expuesto su opinión sobre los supuestos conflictos entre derechos humanos, me propongo ahora seleccionar unos pocos, que estimo representativos de la situación actual. Mi intención no es, desde luego, resumir la doctrina de cada uno, sino utilizar sus obras, consideradas de manera conjunta, para mostrar el contexto dogmático en el que mi propuesta iusfilosófica metodológica puede ser recibida. Pienso que, con tal fin, nos basta con observar la fluctuante terminología, que, en realidad, no es un obstáculo mayor para nuestros fines, y después comprobar la

23 GARCÍA-Huidobro (1993) y Miranda (2006) pp. 229-237. 
variedad de posiciones respecto de la existencia o no de auténticos conflictos o colisiones entre derechos humanos y respecto de los métodos para solucionarlos. De manera que respecto de cada autor me referiré primero a su terminología, para justificar mi opción -sin duda simplificadora- de hablar simplemente de "derechos humanos". Después, en segundo lugar, indicaré su posición sobre la existencia de colisiones entre derechos, es decir, sobre si considera que realmente hay conflictos o que se trata de colisiones aparentes o conflictos entre pretensiones jurídicas. En relación con este punto, como se verá, adhiero a la tesis de que bajo esta discusión puede esconderse una discrepancia meramente terminológica, sin consecuencias prácticas, aunque mi posición iusrealista clásica me incline a hablar más de conflictos de pretensiones - no resueltas antes de la judicación- que de auténticos conflictos de derechos - los cuales exigirían realmente "sacrificar" (¿violar?) algunos derechos para satisfacer otros-. Finalmente, en tercer lugar, aunque de manera simultánea al considerar a cada autor, sintetizó la correspondiente visión acerca de cómo solucionar las colisiones entre derechos humanos (reales o aparentes).

Sin perjuicio del valor de muchas otras exposiciones de la dogmática constitucional chilena, he seleccionado solamente a los siguientes autores, a título ejemplar: Alejandro Silva Bascuñán, José Luis Cea Egaña, Ángela Vivanco Martínez, Eduardo Aldunate Lizana, Joaquín García-Huidobro Correa y Soledad Bertelsen Simonetti. Las razones fundamentales para esta selección son que ellos representan algunas de las posturas claves en el debate, aunque no sean los únicos expositores de cada una; algunos de ellos recogen en sus obras una síntesis de lo que han expuesto precedentemente otros destacados cultivadores de la dogmática constitucional chilena, que menciono solamente, de manera que los lectores situados en otras áreas de la ciencia jurídica y de la filosofía del derecho quedarán bien informados sobre las coordenadas básicas de la discusión dogmática; y, por último, en el caso de la profesora Bertelsen, porque, aunque se trata de una autora en los inicios de su aportación a la dogmática constitucional, su texto, en vías de ser publicado, es el último y más extenso estado actual de la cuestión.

Alejandro Silva Bascuñán -de quien consideraremos solamente las obras más recientes-, en su perspectiva hermenéutica de "dar primacía a lo que el constituyente quiere" 24 , no tiene dificultades para armonizar las denominaciones "derechos humanos", "garantías constitucionales", "derechos fundamentales" y "derechos naturales" o, principalmente, "derechos esenciales que emanan de la naturaleza humana", pues considera que la Constitución chilena ha asumido expresamente la visión iusnturalista al reconocer como límite al ejercicio de la soberanía los derechos esenciales que emanan de la naturaleza humana ${ }^{25}$. Por eso, en el caso chileno es una regla de derecho positivo que la norma superior y siempre vigente del derecho natural condiciona la interpretación constitucional y su posterior aplicación ${ }^{26}$. No es de extrañar, entonces, que el asunto terminológico sea poco relevante, cuando resulta que el debate sobre el verdadero alcance de un derecho -llámesele como se lo llame- no depende de que se le llame o no "natural". En

\footnotetext{
24 SILVA BASCUÑÁN (1997) p. 156.

25 SiLVA BASCUÑÁN (1997) p. 157.

26 SiLVA BASCUÑÁN (2006) p. 26.
} 
efecto, incluso cuando se adopta la terminología del derecho natural, "no cabe duda de que precisar en determinado aspecto o particular situación o caso específico lo que emana de la naturaleza humana no está dado de inmediato y concretamente, sino que abre a menudo un problema complejo por cuanto es una realidad que se impone tomando en cuenta las pertinentes consideraciones ontológicas, antropológicas, sociológicas y de sicología colectiva, incluso su proyección en las ciencias naturales y biológicas” 27 . En cualquier caso, convenimos con el autor en que usar la expresión "derechos esenciales que emanan de la naturaleza humana” es especialmente adecuado cuando está claro que ella refleja tanto la filosofía del derecho correcta como el texto positivo de la Constitución (artículo 5. ${ }^{\circ}$, inciso $2 .^{\circ}$ ).

En relación a las colisiones de derechos, Silva Bascuñán recoge la doctrina tradicional de que los derechos - abstractamente considerados- no pueden ser, en general, "absolutos" -en el sentido de que bajo su descripción cualquier cosa esté permitida o protegida-, sino que, como indican todas las declaraciones de derechos, deben conjugarse con el bien común, el orden público, la moralidad pública, los derechos de los demás, etc. ${ }^{28}$. De ahí que es posible prever situaciones "en las que se enfrenten, por lo menos aparentemente, uno u otro de los derechos" 29 . Ante estas situaciones, solamente cabe dar criterios hermenéuticos generales, que ordenen armonizar los diversos preceptos, sin excluir la consideración de alguna jerarquía a la luz de la concepción de la persona humana "que se cimiente en lo que ella es, en lo que ella necesita, en lo que ella debe realizar y en lo que ella puede sacrificar porque lo exige la convivencia social" 30 .

José Luis Cea Egaña, por su parte, habla generalmente de "derechos humanos" -como preferimos hacer nosotros en este artículo-, pero también de "derechos fundamentales" 31 y de "derechos esenciales" 32 . La dignidad de la persona humana fundamenta tales derechos, pues los "derechos esenciales que emanan de la naturaleza humana", según la expresión constitucional del artículo $5 .^{\circ}$, inciso $2 .^{\circ}$, son "aquellos inherentes a la dignidad de la persona y reconocidos, nacional e internacionalmente, como derechos humanos, intrínsecos de esa cualidad única que es su fuente" 33 . Los derechos humanos no son absolutos, en el sentido de que pueden ser limitados y su ejercicio puede ser suspendido ${ }^{34}$. En este marco conceptual, la regla general es que las colisiones de derechos humanos son solamente aparentes, es decir, al considerarlos en abstracto y con independencia de la debida interpretación y armonización. Sin embargo, cuando el esfuerzo armonizador no es suficiente para "conjugarlos por entero" 35 , el autor sostiene que se ha de admitir "la idea de jerarquía o gradación, de primacía o preponderancia de

\footnotetext{
27 Silva Bascuñán y Silva Gallinato (2001) p. 250.

28 Silva BASCUÑán (2006) p. 36.

29 Silva BASCUÑÁN (2006) p. 41.

30 Silva BasCuñán (2006) p. 42.

31 CEA (1999) p. 168.

32 CEA (1999) p. 172.

33 CEA (2008) p. 215.

${ }^{34}$ CEA (1999) pp. $154-157$ y $160-162$.

35 CEA (1999) p. 172.
} 
unos sobre otros de esos derechos" 36 . Cea Egaña es uno de los autores que con mayor fuerza ha defendido el criterio de la jerarquización, en el ámbito nacional.

Ángela Vivanco Martínez expone las diversas denominaciones y las connotaciones especiales de cada una: "derechos humanos", "libertades", "garantías", "derechos fundamentales" - a veces con la connotación de derechos mínimos necesarios de todos; otras, con la de aquellos especialmente recogidos y protegidos por la Constitución ${ }^{37}$-, "derechos naturales", "derechos innatos", "derechos de la persona humana"38. Aunque utiliza sobre todo la denominación "derechos humanos", ateniéndose al uso mayoritario hoy -que es el que guía la opción de mi trabajo-, al tratar del tema de los conflictos de derechos usa más la denominación "derechos fundamentales"39. Vivanco también observa que el texto constitucional chileno recoge la hermenéutica iusnaturalista, razón por la cual ninguna enumeración de derecho positivo -como la del artículo 19 de la Constitución chilena- puede ser taxativa ${ }^{40}$. Al tratar de las colisiones de derechos, distingue entre las teorías conflictivistas y las no conflictivistas, y presenta un estado de la discusión similar al que sintetizaremos en los apartados siguientes ${ }^{41}$.

Joaquín García-Huidobro, aunque no escribe estrictamente hablando desde la dogmática constitucional, aporta una perspectiva crítica iusfilosófica para comprender por qué surge el problema -o pseudoproblema, si se quiere- que tratamos. En su caso, el concepto clave es el de derecho subjetivo en el sentido moderno, cuando pasa a ser el centro de la argumentación jurídica ${ }^{42}$. Es el lenguaje moderno de los derechos subjetivos abstractos lo que posibilita el surgimiento de conflictos de derechos, en la medida en que separa los derechos de los deberes u obligaciones. El autor defiende una tesis que, como tesis histórica, nos parece totalmente acertada, y que es, de hecho, la inspiración clásica de lo que defendemos en este trabajo. No es que no haya conflictos, sino que se los plantea de modo diferente: no como oposición de derechos abstractos, sino como una situación concreta en la que debe determinarse si se ha producido o no una ofen$\mathrm{sa}^{43}$. El autor, consciente de que quizás eliminar el lenguaje moderno de los derechos -la solución de Villey- ya no es viable, propone seguir la inspiración hermenéutica de Kaufmann, considerar el derecho como un proceso y admitir que el derecho verdadero aparece solamente en la solución del caso concreto. Así, en acuerdo con la corriente no conflictivista, los conflictos de derechos son aparentes, mientras que lo real es el conflicto de intereses ${ }^{44}$. La solución no puede proceder ni de una jerarquización abstracta, ni de una ponderación de derechos ${ }^{45}$. Finalmente, en relación con las propuestas similares a la que presentaremos nosotros, basadas en identificar algunos derechos humanos que

36 CEA (1999) p. 172.

37 VIVANCO (2007) pp. 419-420.

38 VIVANCO (2007) pp. 419-420.

39 VIVANCO (2007) pp. 434 ss.

40 ViVANCO (2006) pp. 237, 239-240.

41 VIVANCO (2007) pp. 434-438.

42 García-Huidobro (2005) pp. 62-63.

43 García-Huidobro (2005) p. 63.

44 García-Huidobro (2005) p. 65.

45 García-Huidobro (2005) p. 65. 
priman siempre sobre los demás porque se basan en normas morales inexcepcionables -los "absolutos morales", como el no matar al inocente-, advierte que "también estos derechos requieren ser especificados y bien se puede descubrir que no son aplicables al caso en cuestión" 46 . A lo cual cabe responder que tales derechos, los verdaderamente absolutos en el sentido de inexcepcionables, son solamente los que se formulan con todas las especificaciones que describen el tipo de acto siempre prohibido, como veremos más adelante. Por lo tanto, son aplicables siempre que se presente la tentación de realizarlos en el caso de un conflicto de intereses. Entonces se cumple lo que observa García-Huidobro: "Lo que sí sucede en esos casos es que un derecho de tal naturaleza, cuando es debidamente especificado y resulta aplicable a un caso determinado, no puede ser violado en virtud de consideraciones ulteriores relativas a la utilidad o a cualquier otro criterio. Un ejemplo típico es el derecho de un inocente a no ser matado por otro" 47 .

Pablo Ruiz-Tagle Vial, observando la fluctuación terminológica ("derechos naturales", "derechos subjetivos", "libertades públicas", "derechos morales”, etc.), sigue a Peces Barba en la adscripción de diversos significados a cada denominación. En atención a esa diversidad de connotaciones, prefiere hablar de "derechos fundamentales" o de "derechos constitucionales" ${ }^{48}$. El autor, escribiendo en conjunto con Renato Cristi, advierte que en la actualidad "los derechos fundamentales no pueden ser formulados exhaustivamente como reglas, porque se expresan también como principios y valores (dignidad, libertad e igualdad)" ${ }^{49}$. Ahora bien, su preferencia por la denominación "derechos fundamentales" no los compromete con lo que ellos denominan "iusfundamentalismo", que es "la versión más conocida de la teoría constitucional de los derechos", la cual “adopta una perspectiva unilateral en tanto que asigna status moral solo a los derechos individuales como tales" ${ }^{50}$. En efecto, Ruiz-Tagle y Cristi adoptan una doctrina amplia de los derechos fundamentales, que incluye los derechos sociales, político y económicos ${ }^{51}$. Quizás vale la pena acotar que mi propia terminología, más adelante, llama "iusfundamentalismo" a cualquier teoría de los derechos humanos que argumenta en términos de derechos, contraponiendo unos a otros para dar la primacía a alguno sin consideración a los tipos de actos que se legitiman o prohíben. En relación con los conflictos entre derechos humanos, Ruiz-Tagle considera que nuestra historia constitucional "puede entenderse no solo como la historia de la construcción de los órganos del Estado", sino también "como una continua tensión entre diversos derechos fundamentales" 52 . A este respecto, se hace eco de la tesis de Favoreu, según la cual las colisiones entre derechos constituyen una de las formas de limitarlos. "Sin embargo", advierte, "es conveniente tener presente que todas las posibilidades de limitación tienen a su vez su propio límite, que descansa en el

\footnotetext{
46 GARCÍA-Huidobro (2005) p. 67.

47 García-Huidobro (2005) p. 67.

48 RuIZ-TAGLE (2006) p. 267.

49 Ruiz-TAGLE y CRISTI (2006) p. 41.

50 RUIZ-TAGLE y CRISTI (2006) p. 40.

${ }^{51}$ Ruiz-TAgle y CRISTI (2006) p. 40.

52 Ruiz-Tagle (2006) p. 257.
} 
respeto a la esencia de derecho" 53 . El autor no adopta un método propio de solución de conflictos entre derechos, aunque está claro que rechaza el método de la jerarquización de derechos y las teorías de autores como Cea Egaña, Verdugo Marinkovic, Pfeffer Urquiaga y Nogueira Alcalá ${ }^{4}$. Además, una vez rechazada la jerarquía abstracta entre derechos, acepta lo que denomina "una concepción de carácter razonado y parcial" 55 , en la que, para resolver las colisiones, caben los procedimientos de balance, delimitación y ponderación de derechos, incluyendo la consideración de los efectos que producen las decisiones constitucionales ${ }^{56}$.

Eduardo Aldunate Lizana, en un trabajo del año 2005 y en el capítulo XIII de su obra de 2008 -que incorpora sustancialmente el artículo de 2005-57, sintetiza las posiciones de los principales autores precedentes (José Ignacio Martínez Estay, Emilio Pfeffer Urquiaga, José Luis Cea Egaña, Humberto Nogueira Alcalá y Pablo Ruiz-Tagle Vial) ${ }^{58}$. Utiliza la nomenclatura de los "derechos fundamentales", pero nos advierte que se da gran variación terminológica entre los autores aun cuando, en realidad, compartan una concepción de los derechos ${ }^{59}$. Aldunate define la colisión de derechos de una manera práctica, que no exige pronunciarse acerca de la cuestión sustancial de si se trata de colisiones o conflictos reales o aparentes. En efecto, la idea de colisión es correlativa a la de limitación de un derecho por otro, o del límite del ejercicio del derecho de un titular por los derechos de los demás, que es una de las limitaciones tradicionales recogidas en los instrumentos jurídicos de derechos humanos en sus diversos niveles. "Se habla de colisión o choque de derechos fundamentales", afirma Aldunate, "cuando el efecto jurídico de la protección iusfundamental alegada por un sujeto (titular del respectivo derecho) es incompatible con el efecto jurídico perseguido por otro sujeto a partir de un alegato de protección iusfundamental" 60 . Aldunate presenta un argumento posible -no está claro si lo hace suyo o no- según el cual la Constitución chilena, al establecer el recurso de protección (artículo 20), abre la vía para el enfrentamiento de derechos y libertades, de manera que carece de sentido preguntarse por la posibilidad de conflictos entre derechos fundamentales cuando la propia Constitución invita a dicho enfrentamiento. Se trataría solamente de proponer soluciones para los conflictos ${ }^{61}$. Yo pienso que este argumento es una petición de principio, pues el texto constitucional no alude en ningún momento a una colisión de derechos, sino a actos arbitrarios o ilegales -es decir, no amparados por el derecho y, por ende, por ningún derecho fundamental- que amenazan o atentan contra algún derecho fundamental. En consecuencia, en el caso de que las dos partes enfrentadas alegaran hallarse en el ejercicio legítimo de su derecho

\footnotetext{
53 Ruiz-TAgle (2006) p. 271.

${ }^{54}$ Ruiz-TAgLe (2006) pp. 261-262.

55 Ruiz-TAgle (2006) p. 262.

56 Ruiz-TAgLe (2006) p. 263.

57 Aldunate (2005); Aldunate (2008) pp. 269-279.

58 Aldunate (2005) pp. 69-70; AldunAte (2008) pp. 271-273.

59 Aldunate (2005) p. 70; Aldunate (2008) pp. 269 y 270.

60 Aldunate (2005) pp. 69 y 71; Aldunate (2008) pp. 269-270.

61 Aldunate (2005) p. 75; Aldunate (2008) pp. 276 ss.
} 
(v.gr., de la honra vs. la libertad de informar) la Constitución no afirma ni niega que el conflicto sea real o aparente. Enseguida, Aldunate considera y critica las diversas soluciones propuestas: la jerarquización -incluyendo en ella por analogía la tesis estadounidense de las libertades o derechos preferidos, contra lo que opina Ruiz-Tagle ${ }^{62}-$, la ponderación en concreto, la teoría de los límites inmanentes mediante la garantía del contenido esencial, la "óptima protección” de cada derecho mediante fórmulas de "concordancia práctica" o "armonización” ${ }^{63}$. Finalmente, su propuesta de solución apunta en varias direcciones, de las cuales cabe destacar dos: la tesis de que no hay una solución general, sino que la Constitución distingue entre diversos derechos (v.gr., la libertad de enseñanza no está limitada por otros derechos), de manera que las colisiones deben solucionarse de manera diversa según los derechos alegados; y, por otra parte, la tesis de que el uso constitucional de expresiones como "ejercicio legítimo" y "restablecimiento del imperio del derecho" implican que a nivel constitucional no existen criterios que permitan resolver las colisiones de derechos, sino que hay una remisión a las normas de nivel subconstitucional, en las que los jueces deberían hallar los criterios de solución so pena de verse abocados a crear derecho, para lo que no están autorizados ${ }^{64}$. Lo notable de esta propuesta es que, aunque salva la formalidad de la solución entre conflictos entre particulares sometidos por igual a la ley, anula el carácter supralegal de los derechos fundamentales, y, en definitiva, remite a la facultad creadora de derecho del Tribunal Constitucional que deba conocer de la inaplicabilidad de esas leyes cuando se alegue que atentan contra uno de los derechos en conflicto precisamente por el modo de resolver acerca de la legitimidad de su ejercicio. De todas maneras, pienso que el análisis de Aldunate se acerca correctamente a plantear una solución adecuada, porque vuelve a poner en el centro del análisis los actos y omisiones, que podrían ser legítimos o ilegítimos según la totalidad del ordenamiento jurídico ${ }^{65}$, y no en la colisión abstracta de los derechos fundamentales en cuanto tales.

Por último, es oportuno remitirse a la obra reciente, en vías de publicación, de Soledad Bertelsen. Ella sintetiza la cuestión conceptual y terminológica, recorriendo las diversas denominaciones y concepciones, y señalando la diversidad de connotaciones debidas a las filosofías subyacentes: derechos naturales, derechos morales, libertades públicas, derechos públicos subjetivos, derechos fundamentales, derechos humanos y derechos constitucionales ${ }^{66}$. Enseguida, expone las principales discusiones sobre las ca-

62 Aldunate (2005) p. 73; Aldunate (2008) p. 273. Ruiz-TAgle (2006) p. 263 afirma que "otorgarle a alguno de estos derechos una posición preferida es también una técnica razonada y parcial”, que se opone a la jerarquización -que Ruiz-Tagle considera "intuitiva”-, porque la posición preferida es otorgada a algún derecho como la libertad de expresión o la propiedad "siempre en el contexto de un caso y evitando generalizaciones de carácter total, o la construcción de una jerarquía”. Dejo a los constitucionalistas adjudicar entre Aldunate y Ruiz-Tagle, aunque me inclino a concordar con Aldunate, en el sentido de que unas libertades o derechos preferidos parecen también superiores, si priman sobre los no preferidos, como la libertad de expresión triunfa sobre la honra o la intimidad según la concepción liberal de esa libertad.

63 Aldunate (2005) pp. 72-74; Aldunate (2008) pp. 273-279.

${ }^{64}$ AldunATE (2005) pp. 75-78; AldunATE (2008) pp. 278-279.

${ }^{65}$ Aldunate (2005) pp. 77-78; Aldunate (2008) p. 279.

${ }^{66}$ Bertelesen (2009) pp. 4-7. 
racterísticas y el fundamento de tales derechos ${ }^{67}$, para enmarcar adecuadamente el problema central de los llamados "conflictos entre derechos fundamentales". Acertadamente, advierte que la concepción moderna de los derechos abstractos tenderá a interpretar las controversias sobre derechos como verdaderas colisiones, mientras que la concepción iusnaturalista clásica considerará los derechos naturales como ajustados, delimitados y correlativos a los deberes, de manera que los choques se dan entre aspiraciones y pretensiones, mas no realmente entre los derechos ${ }^{68}$. Tras recordar y también criticar o matizar algunos criterios de interpretación constitucional ${ }^{69}$, analiza críticamente las principales soluciones propuestas por la doctrina y la jurisprudencia comparada: la jerarquización ${ }^{70}$, que incluye la doctrina de las libertades preferidas (y, contra lo que intuye Ruiz-Tagle, ha sido usada también fuera de los ámbitos pontificios); la ponderación abstracta y la ponderación concreta o ad $h o c^{71}$, la articulación de límites internos o externos ${ }^{72}$ y la delimitación y salvaguarda del contenido esencial de los derechos ${ }^{73}$.

A lo largo de su análisis crítico, Bertelsen se adhiere razonadamente a una concepción de los derechos fundamentales como derechos naturales y se acerca a las soluciones no conflictivistas, es decir, a aquellas que no aceptan que exista un conflicto real entre derechos fundamentales, sino solamente un conflicto aparente o conflicto entre pretensiones jurídicas, las cuales, una vez examinadas con un método adecuado, no chocan realmente. En tal planteamiento, solamente subsisten como alternativas coherentes los métodos basados en la delimitación (o límites internos) y la determinación del contenido esencial de los derechos. La autora argumenta a favor de una metodología de razonamiento basada sobre todo en el contenido esencial de los derechos.

Por último, cabe destacar que Bertelsen hace amplio uso de la jurisprudencia del Tribunal Constitucional y de la Corte Suprema en casos de supuestas colisiones de derechos fundamentales. La culminación de la obra es el intento de mostrar con jurisprudencia del recurso de protección que el razonamiento judicial chileno, en casos importantes sobre diversas materias como libertad de enseñanza, libertad de expresión, honra, intimidad, propiedad privada, etc., ha utilizado implícitamente una metodología de armonización, no conflictivista, atenta a los contenidos esenciales y al ejercicio legítimo de los derechos ${ }^{74}$. Este análisis y su propuesta, en la medida en que toma en cuenta la centralidad de los actos y omisiones ilegales y/o arbitrarios que, de acuerdo con el texto constitucional, pueden atentar contra el legítimo ejercicio de los derechos protegidos, apunta en la dirección correcta que, desde una perspectiva iusfilosófica, intento defender en este artículo.

Los apartados siguientes volverán a considerar algunas de estas posiciones, pero ahora solamente en la medida necesaria para defender la tesis iusfilosófica -con implica-

67 BERTELESEN (2009) pp. 8-16.

68 BERTELESEN (2009) pp. 16-17.

69 Bertelesen (2009) pp. 18-26.

70 Bertelesen (2009) pp. 27-36.

71 Bertelesen (2009) pp. 37-52.

72 Bertelesen (2009) pp. 53-66.

73 Bertelesen (2009) pp. 67-84.

74 Bertelesen (2009) pp. 85-112. 
ciones para la ética judicial- de la primacía del razonamiento práctico sobre tipos de actos y su adecuada especificación.

\section{LA ARGUMENTACIÓN IUSFUNDAMENTALISTA}

La argumentación iusfundamentalista procura resolver una disputa jurídica utilizando como categoría fundamental del razonamiento práctico jurídico la de los derechos subjetivos y, más concretamente, la de los derechos fundamentales. Se pretende que el significado y alcance de un determinado derecho fundamental implica una conclusión práctica respecto de un caso particular. La apelación al derecho fundamental, interpretado de determinada manera, se presenta como razón suficiente para hacer lugar a la pretensión de una de las partes.

En una cultura jurídica legalista, o normativista, los argumentos eficaces tendrán la forma de la subsunción y de la inferencia: el caso cae bajo tal norma, la norma exige tal respuesta o sanción (judicial), luego se exige esa respuesta como resultado del proceso. Pensemos en este ejemplo. Andrés es detenido por la policía sin orden judicial; la norma establece que no está permitido a la policía detener sin orden del juez y que el juez ordenará liberar a cualquiera así detenido; luego, Pedro, apelando a esa norma y probando esos hechos, pide la conclusión: que se ordene su libertad. En cambio, en una cultura iusfundamentalista podría no existir la norma precisa citada -por ejemplo, la que estableciera el habeas corpus-, pero Andrés igualmente podría pedir su libertad apelando al derecho fundamental a la libertad personal y mostrando que ha sido violado. Naturalmente, no existe una cultura puramente legalista, ni una cultura puramente iusfundamentalista, pero sí ha ido formándose una cultura en la que, además de la apelación a las normas que resulten favorables, se admite apelar a estándares abiertos como los principios y valores constitucionales y los derechos esenciales de la persona humana.

La argumentación iusfundamentalista se basa, pues, en dos elementos: los enunciados abstractos de los derechos fundamentales (el derecho a la vida, a la libertad, a la honra, a la libertad de expresión, a la propiedad, etc.) y una interpretación favorable o expansiva del derecho fundamental que se alega en los casos calificados como de conflicto entre el derecho fundamental de una persona y el mismo u otro derecho fundamental de otra persona o algún bien público (o el bien común).

Los ejemplos son de sobra conocidos. Se contrapone la libertad de expresión (free speech), como derecho fundamental, a la seguridad nacional, como bien público. La autoridad a cargo del bien común, molesta por determinados usos (o abusos, en su opinión) de la libertad de expresión, prohíbe determinados actos (v.gr., quemar la bandera nacional o la cartilla de reclutamiento militar). Los afectados acuden a los tribunales para proteger su derecho fundamental. Los tribunales, normalmente, intuitivamente, advierten que puede haber casos en los que sea injusto prohibir algunas manifestaciones de la libre expresión, pero que podría haber otros casos ( $v . g r$., relacionados con la revelación de secretos de Estado, o con la difusión de la pornografía infantil) en los cuales las prohibiciones se justificarían. Ahora bien, resulta patente que si la mera 
apelación al derecho abstracto a la libertad de expresión como superior al bien público y al alcance de las potestades de la autoridad fuera el argumento suficiente para fundamentar una sentencia, siempre debería fallarse a favor de la libertad de expresión. En cambio, la jurisprudencia no se cansa de advertir que no hay derechos absolutos, en el sentido de ilimitados o que no cedan ante ningún otro derecho o interés. En el ejemplo propuesto, la jurisprudencia estadounidense ha desarrollado la doctrina del "peligro claro e inminente" ("clear and present danger") para restringir excepcionalmente la libertad de expresión.

Análogamente, la jurisprudencia articula criterios de delimitación de la libertad de expresión cuando se dice que entra en conflicto con la honra, o con el debido proceso de personas acusadas de delitos (que tienen su propio derecho fundamental a la presunción de inocencia y a un juicio justo), o con la intimidad personal, o con el derecho de propiedad sobre los contenidos usados en una concreta expresión verbal o artística. Y así pueden ponerse otros ejemplos: la libertad de unos contra la propiedad de otros; la vida o la salud de unos contra la vida o la salud de otros; la libertad de empresa contra el derecho a un medio ambiente no contaminado; etc.

Este modo de proceder -inventar criterios de delimitación de los derechos- es imprescindible para salvar la distancia entre el significado abstracto de los derechos y sus exigencias en concreto. Como ha hecho notar Ronald Dworkin, es necesario un proceso de concreción guiado por principios ${ }^{75}$. Sin embargo, los esfuerzos que hacen los jueces por argumentar en términos de derechos -aunque lleguen a soluciones prudentes, intuitivamente justas-, es decir: de la "esencia" de esos derechos, de sus "límites internos", sus "límites externos", sus "excepciones justificadas"... son esfuerzos que no anulan sino que ponen de manifiesto las deficiencias de la argumentación iusfundamentalista. Algunas de estas deficiencias son las siguientes:

1. ${ }^{a}$ El empobrecimiento del discurso jurídico. Los juristas dejan de buscar la acción correcta/justa, que depende de principios muchas veces sutiles y de concreciones normativas muchas veces técnicas (formalismos imprescindibles para un sistema jurídico riguroso), para concentrarse en blandir, con argumentos ad hoc, los derechos fundamentales que les favorecen en cada caso. Naturalmente, como ha señalado Mary Ann Glendon, se produce una inflación de los derechos y su consiguiente desvalorización. "Gente agradable a lo largo de todo Estados Unidos (...) despliegan a menudo la retórica de los derechos como si ellos y sus intereses particulares prevalecieran sobre todo lo demás a la vista"76. "Las pretensiones de absolutidad presentan el efecto malo adicional de que tienden a degradar los derechos a meras expresiones de deseos y apetencias ilimitados"77.

2. ${ }^{a}$ La afirmación simultánea de derechos incompatibles. La creencia en que la premisa cognitivo-normativa en el razonamiento jurídico (correspondiente a la segunda premisa del silogismo práctico, pues la primera y general es intocable: corresponde al compromiso institucional de hacer justicia conforme al derecho) se establece mediante

\footnotetext{
75 DWORKIN (1986) pp. 293 ss.

76 GLENDON (1991) p. 19.

77 GLENDON (1991) p. 45.
} 
-y exclusivamente mediante- la apelación al derecho fundamental que se quiere hacer prevalecer, aboca a la creencia en los llamados conflictos de derechos fundamentales, y a la articulación de una teoría de los derechos fundamentales construida de tal manera que pueda armonizar los derechos entre sí y resolver los inevitables conflictos entre ellos. Existe una correlación entre cada teoría de los derechos fundamentales y la correspondiente teoría de los conflictos de derechos. La consecuencia es que se afirman a la vez derechos humanos incompatibles entre sí (v.gr., la incompatibilidad entre la libertad sexual de la mujer -o su derecho de autodeterminación reproductiva- y el derecho a la vida del embrión, o entre el derecho a la libertad de expresión y la honra o la intimidad). Esta afirmación mina por su base la idea fuerte de los derechos como salvaguardas contra los abusos de los poderosos, que son, en cada caso, los favorecidos por la interpretación del derecho triunfante. Así, como ha mostrado Juan Cianciardo, el lenguaje conflictivista implica una tríada que se anula a sí misma: primero se afirma cada derecho como "fundamental" o "humano" o "natural"; en segundo lugar, se comprueba la colisión de derechos y se declara el conflicto (si es entre "derechos" o entre "pretensiones", no importa demasiado por ahora); para, en tercer lugar, mediante argumentos expansivos de un derecho y restrictivos de otro (siempre existen en las dos direcciones), afirmar que existe un "sacrificio justificado" de aquel derecho que resulta derrotado en este proceso $^{78}$.

Mas entonces la idea de un derecho "justificadamente sacrificado" solamente puede defenderse, contra el cargo de justificar la violación de un derecho humano, por estipulación, es decir, por definición: no es violación del derecho porque su sacrificio, frente a un derecho más valioso, o en un caso concreto donde resulta derrotado, está justificado. Salta a la vista el grave inconveniente de la solución. La misma idea de los derechos naturales implicaba su inalienabilidad, su inmunidad respecto de cualquier conculcación. Afirmar que las violaciones de los derechos humanos desaparecen por arte de definición, cuando los actos que los sacrifican están justificados... eso equivale a enterrar la idea racional de los derechos indisponibles.

\section{LAS SOLUCIONES A LOS CONFLICTOS DE DERECHOS}

Las soluciones propuestas para este callejón sin salida son todas valiosas, y proceden de juristas que advierten la arbitrariedad a la que aboca el discurso de los derechos abstractos. Sin embargo, todas ellas siguen en la órbita de considerar los derechos mismos como pieza fundamental de la argumentación, mientras que nosotros proponemos volver a un razonamiento normativo más formal orientado a la acción.

Una primera solución consiste en categorizar y/o jerarquizar los derechos. "De este modo, en un litigio donde confluyan dos derechos fundamentales se recurrirá a una tabla pretasada de importancia, según diversos baremos, que permitirá establecer la primacía del jerárquicamente superior"79. Así se afirma, por ejemplo, que el derecho

\footnotetext{
78 Cianciardo (2000).

79 Serna y TOller (2000) 7. Véanse pp. 7-10.
} 
a la vida es el primero y fundamental. En caso de conflicto, prima sobre cualquier otro derecho. Así se decide que quien se niega a una transfusión sanguínea puede ser obligado, porque nada lo autoriza a atentar contra su propia vida. En contra, se afirma que el derecho a la libertad de conciencia es más importante, porque refleja de manera inmediata el sentido de la dignidad propia de cada persona. Así se dictamina que nadie puede obligar a alguien a seguir un tratamiento contrario a su conciencia, aunque muera. La solución de jerarquizar los derechos -cualquiera sea la jerarquía que se adopte- tiene la ventaja de su sencillez, pero ha sido objeto de numerosas críticas. La principal objeción es que parece que siempre hay argumentos para considerar cualquiera de los derechos humanos centrales como superior por sí mismo a algún otro en conflicto. Naturalmente, no se habla de la comparación abstracta entre algún derecho central y algún derecho derivado (v.gr., entre el derecho a la vida y el derecho a la salud), donde nadie discreparía sobre cuál está por encima en la jerarquía. Sin embargo, existen derechos que parecen presentar pretensiones de superioridad inconmensurables (v.gr., el derecho a la vida $v s$. el derecho a la libertad de conciencia). Entonces la jerarquización, que termina dando siempre el triunfo al derecho superior en cualquier conflicto, parece arbitraria. "La jerarquización de los derechos no tiene en cuenta la complejidad de este tipo de problemas y la multiplicidad de excepciones y matices que ofrece la vida práctica" ${ }^{80}$. Por eso, su aplicación a ultranza arroja resultados contraintuitivos en los casos en que una excepción parece justificada; por ejemplo, cuando se considera legítimo que alguien sacrifique su vida por ser fiel a su conciencia o por defender la libertad.

Los críticos abandonan, pues, el criterio de la jerarquización. Sin embargo, no es raro encontrar que los mismos que criticaban la jerarquización para oponerse, por ejemplo, a una primacía del derecho a la vida sobre la libertad de conciencia, terminen por hallar su propio derecho preferido. Así, por ejemplo, no creen que exista la tal jerarquía de derechos, pero otorgan a la libertad de expresión un valor preferente por su función estratégica en el funcionamiento del sistema democrático. Finalmente, la solución a favor de la libertad de expresión equivale a establecer una jerarquía, pero no ya por el valor de los derechos de las personas, sino por el valor de un bien público (el sistema democrático).

Lo que hace plausible las jerarquizaciones entre derechos es, a mi modo de ver, la distinción implícita entre tipos de actos que normalmente constituyen el ejercicio o la conculcación de esos derechos. Así, por ejemplo, el asesinato es siempre un tipo de acto antijurídico, mientras que no todo ejercicio de la libertad de conciencia es ipso facto conforme a derecho. De ahí la intuición de que el derecho a la vida, conculcado por el asesinato, es superior a la libertad de conciencia. Sin embargo, si el punto no se establece por referencia explícita a los tipos de actos, se pierde de vista que puede haber algún ejercicio de la libertad de conciencia que sea legítimo y que, aunque conlleve aceptar la muerte, no equivalga a cometer un asesinato (me refiero al homicidio directo del inocente, en sentido objetivo: el que está en una posición objetivamente justa), Por eso,

80 SERNA y TOLLER (2000) p. 26. 
Javier Hervada puede resolver adecuadamente el problema de la objeción de conciencia de los testigos de Jehová después de argumentar acerca del tipo de acto que ellos eligen, que no es suicida ${ }^{81}$. Esta distinción no puede hacerse cuando nos limitamos a contraponer dos derechos muy importantes y a declarar uno de ellos vencedor en el proceso de jerarquización.

Estas dificultades están presentes, de alguna manera, en las otras formas de solucionar los supuestos conflictos de derechos. La segunda de ellas consiste en sopesar los derechos o lograr un equilibrio entre sus exigencias. "Suele ser llamado balancing test o ponderación, y consiste en contrapesar los bienes jurídicos en lisa -intereses públicos y/o derechos individuales- de acuerdo con las circunstancias del caso, para determinar cuál es más importante o "pesa" más en el supuesto y cuál debe rendirse" 82 . El balancing test pone cada derecho en un platillo de la balanza, y enseguida se argumenta para establecer cuál pesa más. Este procedimiento puede realizarse en abstracto (balancing amplio) ${ }^{83}$ o en concreto (balancing estricto) ${ }^{84}$. El sopesar los derechos en abstracto, según su significado o el valor de los bienes protegidos considerados con independencia del contexto concreto en que pueda producirse un conflicto, termina en el establecimiento de una jerarquía, con las dificultades ya mencionadas. Por su parte, el sopesar los derechos en concreto, que tiene la ventaja de diferenciar entre los contextos de acción, aboca frecuentemente a una argumentación ad hoc que se resuelve mediante alguna forma de consecuencialismo. Nunca hay un derecho que tenga, ni siquiera prima facie, mayor valor que otro, sino que en cada caso se han de sopesar las consecuencias buenas y malas de adjudicar a favor o en contra de cada una de las partes en el conflicto. La principal objeción contra una solución ad hoc, de tipo consecuencialista, es que un estricto consecuencialismo del acto elimina el carácter universal e inalienable de todos los derechos fundamentales, cuando sucede que, como observa Cianciardo, "si hay algo que ha caracterizado al discurso de los derechos humanos desde su aparición es, justamente, su resistencia a la postergación" 85 . El método de la ponderación ad hoc implica que siempre podría justificarse el sacrificio de un derecho, aunque, por un asunto meramente definicional, no se lo denominara, al sacrificio, violación del derecho ${ }^{86}$. Si se adopta un consecuencialismo de la regla, en realidad no se realiza un balancing ad hoc, caso a caso, sino que se aplica al caso la regla más o menos general (o universal) que se considera justificada. Si esa regla se formula en términos de derechos humanos que superan o derrotan a otros siempre -

\footnotetext{
${ }^{81}$ Hervada (1993b).

82 SERna y TOller (2000) p. 10.

83 SERna y TOller (2000) p. 10.

${ }^{84}$ SERna y TOlLer (2000) p. 11.

85 Cianciardo (2000) p. 118.

${ }^{86}$ H. L. A. Hart muestra las dificultades del utilitarismo para acomodar la noción de derechos naturales. Bentham los considera "tonterías en zancos" (nonsense upon stilts), pues si hay razones morales para que se reconozcan determinados derechos (es decir, para que la ley los establezca como derechos) esas razones se fundan en el principio de utilidad y no en supuestos derechos morales anteriores a los derechos legales. Mill procura justificar tales derechos, pero reconoce que pueden ser superados por consideraciones de utilidad. Véase HART (1982).
} 
porque esa superioridad garantiza las mejores consecuencias en la generalidad de los casos-, entonces estamos de regreso en la jerarquización, con sus problemas de ceguera ante los tipos de actos relacionados con cada derecho. En cambio, si la regla se formula en términos de actos debidos en general o universalmente (i.e., con independencia del cálculo utilitarista respecto de cada acto en su contexto de acción), algunos de los cuales resguardan un derecho fundamental, y otros, otro derecho o bien humano (incluso colectivo), entonces se ha abandonado la argumentación iusfundamentalista, que es lo que propongo.

La tercera fórmula propuesta en el marco de la argumentación iusfundamentalista consiste en establecer límites externos a los derechos ${ }^{87}$. Los derechos se formulan, entonces, siempre como limitados por algún límite configurado de manera abierta: los derechos de los demás, el bienestar general, el orden público... No hay nada que objetar a la formulación general, que refleja el carácter limitado de los derechos humanos; pero estas fórmulas no solucionan el problema hermenéutico, que se traslada a la fijación de esos límites ya sea en general, ya sea en concreto.

La fórmula de los límites externos admite que existen los conflictos de derechos. A ella, tanto como a las otras soluciones, se ha opuesto lo que algunos autores -como Serna, Toller y Cianciardo- han denominado no-conflictivismo: la afirmación de que los derechos verdaderamente existentes no colisionan entre sí, porque poseen un significado internamente delimitado ${ }^{88}$. Esta respuesta contrapone, a los límites externos, los límites internos o delimitaciones; pero no excluye la existencia de límites externos, expresamente previstos por las formulaciones típicas de los derechos.

El conflictivismo y el no conflictivismo, que a algunos puede parecerles una contraposición fundamental, persiguen, en realidad, el mismo objetivo con una diferencia de lenguaje. El conflictivismo habla de conflictos (reales) entre derechos, de manera que los derechos deben ser jerarquizados o equilibrados o limitados para resolver los conflictos. Necesariamente se ha de sacrificar (realmente) un derecho fundamental, justificadamente. Este lenguaje implica, quizás, una diferencia de fondo en la concepción ética subyacente: la idea de sacrificar justificadamente un derecho disuelve la comprensión de los derechos humanos como ciertos bienes de cada uno, realmente indisponibles e inviolables. Por su parte, el no conflictivismo habla de conflicto solamente aparente de derechos, o bien de conflicto y contraposición de pretensiones jurídicas. Entonces nunca es necesario sacrificar un derecho fundamental para favorecer al que pesa más, en concreto o en abstracto, o al que es intrínsecamente superior según una determinada jerarquía de derechos. Solamente es necesario determinar el significado y alcance real de cada derecho, lo cual, si se realiza mediante un razonamiento jurídico universalizable, demuestra que realmente no chocaban los derechos mismos, sino que una de las partes tenía una pretensión no cubierta por el derecho fundamental al cual apelaba ${ }^{89}$.

87 SERna y TOLLER (2000) pp. 19-21.

88 SERna y TOLler (2000) pp. 37-75.

89 Véase la exposición más detallada de CiAnCIARDO (2000) pp. 247 ss. 


\section{LA ARBITRARIEDAD JUDICIAL Y LA HIPOCRESÍA EN LA ARGUMENTACIÓN JURÍDICA}

La mayoría de la soluciones pierden de vista la teoría de la acción humana. Razonan en términos de oposición entre derechos fundamentales y no de acciones debidas o indebidas según la justicia o, si incorporamos las restricciones institucionales del derecho positivo, según la justicia conforme al derecho. Los pensadores más coherentes, ante este tipo de contraposición, concluyen en uno de dos extremos: o afirman que los derechos naturales colisionan necesariamente, hasta el punto de que toda solución pasa por renunciar en alguna medida a ellos, como afirma Hobbes ${ }^{90}$, o bien, por el contrario, niegan que tenga sentido hablar de "derechos naturales" con independencia de las leyes que establecen los derechos (así Bentham, quien llamó a los derechos naturales revolucionarios "tonterías en zancos" $\left.{ }^{91}\right)$.

En mi opinión, lo que más incomoda al jurista, que profesionalmente está inclinado a buscar la seguridad en las relaciones de justicia, es que el uso indiscriminado de la argumentación iusfundamentalista parece abocar a alguna forma de arbitrariedad.

Las jerarquizaciones consideran solamente los bienes (o intereses) protegidos por el enunciado abstracto de los derechos fundamentales, lo cual lleva a la arbitrariedad a la hora de señalar uno como absolutamente superior a los otros. Esto se debe al olvido del contexto de acción donde cobran significado de justicia o de injusticia los actos que tratan con esos bienes. Siempre es injusto el homicidio (asesinato con todos sus rasgos definidores), la calumnia, la coacción para abrazar una fe religiosa; pero no siempre es injusto un acto que resulta en la muerte de alguien ( $v . g r$., una operación quirúrgica con asunción de un riesgo permitido o proporcionado), o en daño de su fama (v.gr., la denuncia de un delito, fundada o razonablemente atribuido a alguien), o en hostilidad para una determinada convicción religiosa ( v.gr., la prohibición de sacrificios humanos o de consumo ritual de estupefacientes). La frontera que divide lo justo y lo injusto no tiene que ver con los bienes (o intereses) afectados, ni tampoco, por tanto, con los derechos fundamentales que se enuncian para amparar esos bienes en un sistema jurídico de protección que ha optado por la categoría de los derechos fundamentales para expresar y asegurar el respeto a lo que es justo.

De manera análoga, la ponderaciones, cuando no equivalen a la jerarquización, se olvidan de los tipos de acciones en general y se remiten a un cálculo ad casum. Aparentemente, esta solución incurre en el defecto contrario: le da demasiada importancia al contexto de acción. Sin embargo, lo hace de tal manera que ya no tiene sentido usar ni la categoría de los derechos humanos, ni la especificación abstracta de actos siempre injustos, para salvaguardar la justicia y proteger determinados bienes debidos a cada

\footnotetext{
${ }^{90}$ Hobbes, por una parte, afirma que se puede consentir en cualquier daño, y, entonces, no se comete injusticia contra quien ha consentido (Leviathan XV y XVII); pero, por otra parte, afirma que algunos derechos no pueden ser renunciados y el pacto en que se renuncian es inválido (Leviathan XIV y XXI). En cualquier caso, está claro que la única forma de vivir en paz es mediante una amplia renuncia de los derechos naturales en favor del soberano. Véase someramente FASSÒ (1982a) pp. 100-105.

${ }^{91}$ FASSÒ (1982b) p. 31 y HART (1982).
} 
uno. Si ya no hay determinados bienes que no puedan ser objeto de disposición directa, es decir, si respecto de ellos no hay al menos algunos tipos de actos siempre injustos por su objeto, entonces la solución de los casos difíciles siempre requerirá una decisión ad hoc impredecible por referencia a los estándares generales precedentes. Este inconveniente hace inútiles los estándares precedentes. Además, puesto que la acción correcta no podía ser prevista mediante estándares precedentes, tampoco puede ser realmente justificada una decisión concreta por referencia a los derechos humanos, que no valen como estándares precedentes.

Con otras palabras, tanto la jerarquización como la ponderación de los derechos fundamentales parecen abocar a alguna forma de arbitrariedad. La solución de los límites externos (compatibilizar derechos con otros derechos y con otros bienes, como la salud pública, la moral, el bien común, etc.) y la de los límites internos (determinar la esencia abstracta, intangible, de los derechos) constituyen, en realidad, remisiones a un proceso ulterior de especificación de los derechos, a lo cual me referiré enseguida. Mi punto ahora es que los procedimientos realmente usados in concreto -la jerarquización y la ponderación en la jurisprudencia sobre supuestos conflictos de derechos-, puesto que realmente no sirven para arribar a una solución razonable, abocan a la arbitrariedad. El juzgador, privado de criterios prudenciales de solución justa, hace valer ya la jerarquía, ya la excepción a la jerarquía; ya una ponderación de un derecho como superior, ya la del contrario, según lo que intuitivamente - muchas veces, con el acierto propio del juez prudente- piensa que es la solución justa.

Volvamos a los ejemplos. Si la vida es un bien de jerarquía superior, entonces el juez debe hacerla respetar siempre, por encima de cualquier otro interés; y así suele hacerlo, contra quienes amenazan con cometer homicidio o someter la vida humana a un riesgo intolerable. Sin embargo, surgen casos que hacen dudar de esta jerarquización específica, como, por ejemplo, si puede ser razonable forzar a una persona a recibir una terapia contraria a su propia conciencia (asumida como errónea). Entonces se encuentra alguna forma de hacer excepción a la jerarquía, como, por ejemplo, afirmar que en estos casos prima la dignidad de la persona y su autonomía para elegir un tratamiento. ¿Y por qué no en otros casos, como los de suicidio o eutanasia? Algunos, porque intuitivamente son partidarios de la licitud del suicidio y de la eutanasia, procuran, entonces, invertir la jerarquía: la autonomía siempre es superior a la vida. Y entonces surgen los casos en que intuitivamente no estarían de acuerdo: un hombre sano que consiente en ser despedazado como espectáculo, a cambio de un precio para su familia empobrecida; un grupo religioso que ofrece sacrificios humanos, con el consentimiento de las víctimas adultas; o, más realistamente (por ahora), los casos de eutanasia que caen fuera de la ley que la legaliza ( $v . g r$. , no se ve por qué esperar a que la persona sufra o esté enferma o anciana). Y así sucesivamente: lo que parece una jerarquización objetiva se torna arbitrario a la vista de los casos. Otro ejemplo, quizás más ridículo, es el de la libertad de expresión contra la honra y la intimidad: si aquella fuese más alta en la jerarquía, todos los casos debieran resolverse a su favor. No es así, por criterios que abandonan la idea de jerarquía por alguna forma de ponderación, según los casos. Ahora bien, la ponderación ad casum reviste directamente las apariencias de lo arbitrario. 
En suma, el juez no puede haber llegado a la solución justa del caso ni por jerarquización, ni por ponderación, sino solamente por intuición, o por un razonamiento práctico válido, pero que no se revela ${ }^{92}$. Sin embargo, aquí se introducen, en la filosofía del derecho reciente, dos distinciones emparentadas, una entre explicar una sentencia judicial y justificar la misma sentencia judicial, y otra entre el contexto de descubrimiento y el contexto de justificación de una decisión judicial. Aunque algunos autores las tratan como distinciones diferentes entre sí, las dos apuntan a lo mismo: a separar el proceso interior realmente seguido por el juez (sus motivaciones reales, causales, que pueden ser inaceptables) de las razones objetivas que pueden esgrimirse u oponerse para justificar válidamente su sentencia (razones, principios, normas, según las cuales la sentencia es correcta) $)^{93}$.

Se dice que una cosa es cómo el juez arriba a su sentencia, cuál es el proceso interior de razonamiento que él realmente sigue y/o de motivación irracional. Describirlo es explicar su decisión; es revelar el contexto de descubrimiento, donde los elementos racionales -que podrían eventualmente figurar en una justificación a posteriori- se entremezclan con todo tipo de causalidades y de procesos psicológicos, motivaciones subjetivas, etc. En cambio, otra cosa distinta es cómo argumenta el juez para justificar su sentencia, es decir, para hacerla aceptable o mostrar que es razonable para las partes y para la comunidad. Las razones y los argumentos esgrimidos en el contexto de justificación se rigen por las reglas y los principios de una teoría de la justicia o de una teoría normativa de la argumentación jurídica, y deben apelar a las reglas y principios de la justicia y del derecho vigente, en la medida necesaria para justificar la sentencia. Sin embargo, la justificación es una reconstrucción de razonamientos con vistas al auditorio (contexto de justificación), y no una reproducción del proceso realmente seguido por el juzgador (contexto de descubrimiento).

La serena aceptación de esta dicotomía, de esta separación entre la explicación del proceso realmente seguido para arribar a una sentencia y la justificación a posteriori de esa sentencia mediante argumentos y raciocinios que no necesariamente fueron seguidos o usados en el contexto de descubrimiento, permite "razonar" jurídicamente de la manera que estamos criticando. La omnipresente autoridad justificadora de la apelación a los derechos fundamentales lleva a usarlos en el proceso de justificación, en la fundamentación de las sentencias, y, por ende, en la reconstrucción del derecho vigente que supuestamente sirve para dirigir la acción y para solucionar los conflictos de pretensiones entre las personas. Sin embargo, de hecho esas formas de razonar en términos de derechos humanos que colisionan -de su jerarquía, ponderación, límites, esencias, etc.- no son un reflejo verdadero de lo que realmente ha llevado a los jueces a decidir de esa forma

\footnotetext{
92 Serna y TOLLer (2000) pp. 109 ss., analizan varios casos en los que los jueces resuelven bien la cuestión de fondo, pero donde, al mismo tiempo, todo el planteamiento conflictivista, que envuelve el razonamiento judicial, resulta superfluo.

93 SQUella (2001) pp. 475-479 y AARNIO (1991) pp. 57 ss. Aarnio defiende la necesidad de justificar realmente, es decir, también de atenerse al proceso racional/razonable en el contexto de descubrimiento, durante el trabajo de hallar la solución razonable, que después será exhibido en el contexto de la justificación.
} 
(contexto de descubrimiento, explicación). Los jueces, por lo tanto, pueden no ser ni siquiera conscientes de lo que realmente les lleva a intuir una respuesta justa. Incluso hay quienes afirman que primero intuyen la respuesta y solamente después comienzan a buscar sus argumentos.

Esta situación es inaceptable desde el punto de vista ético y político, porque constituye una combinación de arbitrariedad y de hipocresía. La arbitrariedad judicial socialmente aceptada estriba en que puede arribarse a cualquier solución, mediante procedimientos intuitivos, con tal de encontrar una justificación que supere los mecanismos de control de la arbitrariedad, esto es, con tal de salvar las apariencias. Y esto es hipocresía. La hipocresía judicial socialmente aceptada consiste en que se ocultan las verdaderas razones -quizás hasta se desconocen- bajo el manto de unas razones y argumentos buscados a posteriori -en los que quizás ni siquiera se cree-, con lo cual se deja de proporcionar los fundamentos que realmente tiene una sentencia. Este procedimiento no ayuda a representar continuamente el sistema normativo y/o las exigencias de justicia que realmente dirigen la vida en común. La única forma de superar esta situación, que, en materia de los supuestos conflictos de derechos (o de pretensiones jurídicas), tiende a deslegitimar el lenguaje de los derechos y la misma concepción de los derechos fundamentales, es procurar que el contexto de justificación refleje lo más fielmente posible el contexto de descubrimiento. Este ideal de transparencia del razonamiento judicial es, a su turno, alcanzable solamente si se admiten como justificaciones válidas auténticas formas de raciocinio práctico, y no pseudo-raciocinios construidos sobre la base de contraponer y de equilibrar derechos fundamentales. En esta dirección apunta la recuperación de la filosofía de la acción y del razonamiento práctico en términos de tipos de acciones.

\section{LA ESPECIFICACIÓN DE LOS DERECHOS Y LA ESPECIFICACIÓN DE LOS ACTOS}

Una forma de huir de los inconvenientes señalados, que se aproxima a nuestra propuesta, es la de la especificación de los derechos fundamentales.

Si vamos más allá de las diferencias lingüísticas entre conflictivismo y no conflictivismo, se han intentado diversos modos de presentar la teoría de los derechos humanos (aparte de las estrategias de razonamiento práctico jurídico reseñadas en el apartado precedente) que procuran formularlos de una manera que permita resolver los conflictos o colisiones entre derechos abstractos, o, en el lenguaje no conflictivista, los conflictos entre pretensiones jurídicas concretas fundadas en apelaciones incompatibles a los derechos fundamentales. Estas estrategias, aunque se acercan a lo que ahora proponemos, no disuelven completamente las desventajas de razonar sobre las exigencias de la justicia en términos de derechos fundamentales. De hecho, una de ellas, usada por John Finnis, en quien me inspiro, procura reconducir la teoría de los derechos a una comprensión de la teoría clásica de la acción ${ }^{94}$.

${ }^{94}$ FinNis (1980) pp. 218 ss. 
John Finnis, Ronald Dworkin y otros autores defienden la necesidad de una especificación progresiva de los derechos. Así se afirma que un derecho, enunciado en abstracto, existe en general, a menos que ... Aquí se reconoce que los derechos abstractos son potencialmente ilimitados y conflictivos, y se hace patente la necesidad de concretarlos -en la terminología de Dworkin ${ }^{95}$ - o de especificarlos - en la terminología de Finnis ${ }^{96}$-. En el marco de nuestra investigación sobre la especificación del acto humano, la propuesta de Dworkin supone una apelación a principios (por lo menos a una cierta comprensión de la igualdad liberal) en el caso de la concreción de los derechos en el common law ${ }^{97}$ y una apelación a las leyes en el caso de la concreción de los derechos en los ámbitos legislados (statute law) ${ }^{98}$. En los dos casos, implícitamente se reconoce que la clave de solución de los conflictos entre derechos abstractos o prima facie -según la terminología de Dworkin- estriba en un modo de razonamiento jurídico no centrado en los derechos, que son el problema, sino en los principios y normas que establecen lo que es debido entre las personas supuestamente titulares de los derechos abstractos. De ahí que la posición de Dworkin es consciente de las dificultades de la argumentación iusfundamentalista y apela a los principios (y aun a las reglas legisladas) que subyacen a toda configuración concreta de derechos.

John Finnis, por su parte, propone una especificación por la vía de normas sobre derechos fundamentales, que determinan los tipos de acciones siempre prohibidas, que corresponden a los derechos absolutos, en el sentido de no excepcionables, y los criterios de delimitación, para los derechos afirmativos, que no corresponden a una prohibición correlativa. Esta posición supone remitirse al problema de la especificación del acto humano, y formular derechos absolutos o negativos -los que exigen abstenciones de actos siempre injustos- de manera muy estricta, como, por ejemplo, los de los artículos 4 y 5 de la Declaración Universal: "Nadie estará sometido a esclavitud ni a servidumbre" (Art. 4); "Nadie será sometido a torturas ni a penas o tratos crueles, inhumanos o degradantes" (Art. 5). Es evidente que estos derechos se formulan de manera absoluta y exigen definir los tipos de injusticia mencionados: esclavitud, servidumbre, tortura, etc.

Al mismo tiempo, el contenido específico de los derechos afirmativos -los que exigen prestaciones- ya no puede determinarse apelando a los mismos derechos, pues el procedimiento sería circular, sino por referencia a todo el conjunto de normas que determinan el derecho positivo vigente en una determinada jurisdicción. En los dos casos, Finnis sustrae la solución de las controversias jurídicas sobre derechos del juego irracional que consiste en contraponer derechos fundamentales para jerarquizarlos, equilibrarlos o, en el peor de los casos, entregarlos al cálculo consecuencialista.

\footnotetext{
95 Dworkin habla de "derechos abstractos o prima facie", que pueden entrar en conflicto. Por eso, tratando del conflicto de pretensiones respecto de derechos iguales ( $v$.gr., de propiedad vs. inmunidad contra la contaminación acústica) propone una forma de concretarlos que apela a una concepción de la igualdad o bien a la interpretación de las normas que especifican los derechos en la comunidad. Véase DWORKIN (1986) pp. 293 ss.

96 FINNIS (1980) pp. 218-221.

${ }^{97}$ DwOrKIN (1986) pp. 276-312.

98 DWORKIN (1986) pp. 313-354.
} 
Pedro Serna y Fernando Toller proponen una forma de especificación por la vía de definir el contenido esencial de cada derecho, el cual, siguiendo lo que ha sido establecido en constituciones como la alemana, la española y la chilena, nunca puede ser sacrificado; es decir, normativamente se excluye que pueda existir un "sacrificio justificado" del contenido esencial de un derecho 99 . "Los autores no distinguen entre un núcleo duro indisponible y una parte accidental de los derechos, sino que consideran esencial todo "el amplio ámbito del ejercicio razonable de un derecho"100. Esto supone, a mi modo de ver, una remisión a la especificación de acciones como razonables o no razonables; es decir, también parece aquí que la delimitación de la esencia indisponible depende de una cierta conclusión normativa acerca de qué tipos de actos son inexcepcionablemente injustos, de manera que la legislación que regula los derechos no puede permitir esos tipos de actos a la hora de armonizar unos derechos con los otros.

En consecuencia, como manera de presentar directamente lo que subyace a los intentos de especificación de los derechos o de delimitación de sus contenidos esenciales indisponibles, proponemos acoger en el razonamiento práctico jurídico -y, por ende, en el razonamiento judicial- la tesis de la filosofía de la acción acerca del lugar central que ocupa en la deliberación el conocimiento y la fijación de las especies de los actos humanos. En el marco de esta propuesta, se ha de razonar sobre dos puntos capitales:

a) Sobre los tipos o clases de acciones justas e injustas por sí mismas, o bien justas o injustas a causa de definiciones de derecho positivo. Solamente como consecuencia de esta identificación podrá proseguirse en la deliberación para determinar si algunas acciones concretas, que caen bajo esas descripciones generales, son o no son violaciones de los derechos fundamentales.

b) Sobre la diferencia entre los efectos malos (para un bien o un interés protegido por un derecho fundamental) que son directamente intentados y los que son solamente permitidos (i.e., efectos indirectos o colaterales), porque los actos humanos se especifican -según la filosofía clásica y sus expresiones contemporáneas- solamente por aquello que el agente intenta, en el sentido de querer como fin o como medio. Ciertamente, el agente puede ser responsable por no evitar efectos malos que, aunque no intentados, tiene obligación de evitar; pero, en este caso, la obligación positiva de evitar un efecto malo admite excepciones (v.gr., por imposibilidad física o moral), mientras que la obligación negativa de abstenerse de intentar el acto prohibido puede ser absoluta y no admitir justificación (a veces, ni siquiera excusa). Esto es clave a la hora de trasladar los resultados de la deliberación a una exposición sobre los derechos, porque el agente tiene la obligación de no violar los derechos humanos (definidos de manera estricta); pero no puede tener la obligación de impedir todos los efectos malos que, de haber sido positivamente elegidos, hubieran constituido una violación de esos derechos. Así, en un ejemplo fácil, uno puede tolerar el riesgo para la vida humana que significa conducir un automóvil, y no es responsable de una muerte accidental cuando ha puesto las medidas de prudencia que hacen tolerable el riesgo (pero esa muerte es consecuencia indirecta de su

99 Serna y TOLler (2000) pp. 37-75.

100 SERNA y TOLLER (2000) p. 47. 
elección de conducir). En cambio, quien elige matar a otro, comete homicidio, con independencia del contexto.

Un razonamiento práctico jurídico completo, que quiera fundamentar del todo una decisión, supone algunos conocimientos que no necesariamente se han de explicitar en cada caso, porque habitualmente están implícitos en el sistema cultural, político y jurídico.

Supone, en primer lugar, un reconocimiento de los fines, bienes humanos y principios más básicos del obrar humano, individual y socialmente considerado. A veces, las controversias políticas y éticas nos hacen perder de vista un fondo de acuerdo sobre los valores básicos, que son aquellos a los que precisamente todos apelamos en esas controversias, y que pueden verse buscados y perseguidos en todas las culturas: la vida, la verdad, el bien de todos o bien común, la razonabilidad, la justicia.

En segundo lugar, naturalmente, aparte de esos primeros principios ${ }^{101}$, otros elementos, sobre los que no hay unanimidad, intervienen en la configuración de una visión del hombre y de la comunidad. Esta visión antropológica y ética -especialmente una determinada teoría de la justicia ${ }^{102}$ - influye necesariamente en el razonamiento práctico más inmediato, aun cuando el razonamiento jurídico técnico se aísle parcialmente del razonamiento práctico general. En cualquier caso, en este nivel conviene hacer explícitas estas premisas, mediante un razonamiento práctico -a la vez jurídico y ético- que identifique los tipos de acciones, y distinga al menos tres situaciones:

a) Los actos injustos por su especie, es decir, de suyo y siempre. Solamente ellos dan origen a los derechos absolutos, como se ha indicado. Por el grado de restricción a la libertad que suponen y para no exigir imposibles, se han de definir de modo estricto las especies de tales acciones, aunque a nivel de instrumentos jurídicos sobre derechos humanos se nombren con términos que exigen esa ulterior definición: "esclavitud", “tortura”, etc. Es patente, como muestran estos ejemplos, que los derechos absolutos son solamente un reflejo de lo que se ha concluido acerca de determinadas especies de actos humanos. Por eso, el razonamiento general sobre la especificación de estos actos humanos siempre prohibidos es un requisito imprescindible del razonamiento práctico inmediato en relación con estos tipos de derechos llamados "absolutos".

b) Los actos lícitos, de suyo buenos o indiferentes según su tipo, que podrían llegar a ser tanto permitidos como prohibidos como obligatorios no ya por su significado moral, sino en virtud de concreciones/determinaciones prudenciales establecidas en las leyes (incluyendo aquí la Constitución y los instrumentos internacionales sobre derechos humanos), las costumbres, los precedentes judiciales, etc. Aquí el campo es inmenso, $y$, en este marco, las normas positivas sobre derechos humanos pueden cumplir una función precedente o anterior a la identificación de especies de actos en sentido jurídico como prohibidos, permitidos u obligatorios. Así, por ejemplo, la regulación específica del alcance del derecho de propiedad determina qué actos concretos constituyen por su

101 S. th. I-II, q.94, a. 2, c; Finnis (1998) pp. 79 ss.; GarCía-Huidobro Correa (1993) y Miranda (2006) pp. 229-237.

102 HeRVADA (1993a) pp. 36-39 y 183-188, y FinNis (1980) pp. 3-22 y 351-368. 
especie hurtos, usurpaciones u otras formas de atentar contra la propiedad. De la misma manera, la regulación específica del poder de policía determina qué constituye en especie una detención violatoria de la libertad personal. Así sucede que -como decíamos al comienzo de este artículo- la configuración concreta de los derechos humanos, en su contenido de derecho positivo, incide en la definición de especies de actos jurídicos contrarios.

c) Los actos obligatorios, que siempre lo son solamente en general, porque son objeto de preceptos afirmativos, que obligan según las circunstancias: admiten consideraciones prudenciales y epiqueya (equidad) en los casos particulares. Es necesario determinar cuándo, cómo, a quién y por quién exigir esos actos obligatorios o prestaciones positivas, mientras que las abstenciones de actos de suyo injustos -no cometer injusticia-son exigibles a todos con independencia del contexto ${ }^{103}$.

En síntesis, el camino del razonamiento práctico jurídico parte de fines y principios usualmente implícitos y aceptados por todos; incorpora premisas explícitas tomadas de las reglas éticas y jurídicas relevantes para el caso; delibera sobre los tipos o especies de acciones identificadas según su relación con esas reglas y esos principios precedentes; y, finalmente, arriba a conclusiones acerca de los tipos de actos y los actos concretos debidos o indebidos o permitidos. Los derechos, ya en su formulación abstracta, ya en su determinación concreta en un caso, solamente sirven para expresar esas conclusiones. Esto es así porque el fin de todo razonamiento práctico es decidir sobre acciones, que a su vez versan sobre los bienes humanos que son sus objetos; pero versan de distinta manera sobre esos bienes, según que los afecten directamente o que queden fuera del objeto directo de la acción (efectos colaterales). De manera que no sirve al razonamiento práctico la mera oposición de derechos, que se transforma en un griterío donde se contraponen jerarquizaciones más o menos arbitrarias (con las imprescindibles excepciones a la jerarquía, para salvar la intuición jurídica) o ponderaciones en general o ad hoc incapaces de proporcionar razones justificadoras universalizables.

En consecuencia, si es verdad que los casos solamente pueden resolverse mediante razonamientos prácticos que contienen premisas implícitas muy generales y especialmente una teoría de la justicia, además de las premisas explícitas tomadas de las reglas y principios del derecho positivo, es necesario que el razonamiento práctico jurídico incorpore una correcta teoría del razonamiento práctico y una explícita filosofía moral y política justificada. La teoría correcta del razonamiento jurídico ha de centrarse en los actos que son objeto de deliberación, y no en los derechos humanos usados como categorías conceptuales para indicar aspectos de la justicia y del bien humano que han de ser protegidos. Solamente así podría evitarse que la apelación a unos derechos fundamentales susceptibles de abrazar cualquier conclusión -si nos limitamos a contraponerlos en conflictos irracionales- aboque al más absoluto escepticismo sobre la capacidad del derecho vigente para orientar la conducta de los ciudadanos y el ejercicio de la jurisdicción. Tal escepticismo es natural si la vigente teoría de la fundamentación del discurso judicial combina una creencia en lo incognoscible o lo ignoto del proceso de

103 GEORGE (2009) pp. 5-6. 
descubrimiento de la solución justa -esto equivale a legitimar las intuiciones no razonadas- con una exigencia de justificaciones a posteriori, válidas como razones para el auditorio, pero no descriptivas de las razones auténticamente operativas en el proceso. Tal escepticismo es incompatible con una ciencia jurídica y con una práctica jurídica que tengan como pilares la interdicción de la arbitrariedad y la confianza en la razón: no solamente en la racionalidad estratégica que enmascara la intuición, la justicia bajo la palmera, sino en la razonabilidad práctica prudencial, que realmente dirige los procesos de hallazgo.

\section{BIBLIOGRAFÍA CITADA}

AARNIO, Aulis (1991): Lo racional como razonable. Un tratado sobre la justificación jurídica (Madrid, Centro de Estudios Constitucionales) 313 pp.

AldunATE, Eduardo (2005): "La colisión de derechos fundamentales", Revista Derecho y Humanidades, 11, pp. 69-78.

AldunAte, Eduardo (2008): Los derechos fundamentales (Santiago, LegalPublishing) 439 pp.

AleXY, Robert (1997): Teoría de la argumentación jurídica. La teoría del discurso racional como teoría de la fundamentación jurídica (Madrid, Centro de Estudios Constitucionales) $346 \mathrm{pp}$.

AQUinO, Tomás de (†1274): Summa Theologiae (se cita como S. th., con su división interna clásica).

Bertelesen SimonetTi, Soledad (2009): Métodos de solución de conflictos entre derechos fundamentales (Santiago, Tesis de Licenciatura, pro manuscripto) $127 \mathrm{pp}$.

Cea Egaña, José Luis (1999): El Sistema Constitucional de Chile. Sintesis Crítica (Santiago, Ediciones Facultad de Ciencias Jurídicas y Sociales, Universidad Austral de Chile) 477 pp.

Cea Egaña, José Luis (2008): Derecho Constitucional Chileno (Santiago, Ediciones Universidad Católica de Chile, $2^{\mathrm{a}}$ ed.) tomo I.

CiAnCIARDO, Juan (2000): El conflictivismo en los derechos fundamentales (Madrid, Eunsa) $424 \mathrm{pp}$.

Cruz, Luis M. (2005): La Constitución como orden de valores. Problemas juridicos y políticos (Granada (España), Comares) 147 pp.

DwOrkin, Ronald (1986): Law's Empire (Cambridge, Massachusetts, Harvard University Press) $470 \mathrm{pp}$.

FASSÒ, Guido (1982a): Historia de la Filosofía del Derecho (Madrid: Pirámide) vol. 2.

FASSÒ, Guido (1982b): Historia de la Filosofía del Derecho (Madrid: Pirámide) vol. 3.

FINNIS, John (1980): Natural Law and Natural Rights (Oxford, Oxford University Press) $425 \mathrm{pp}$.

FInNiS, John (1998): Aquinas. Moral, Political, and Legal Theory (Oxford, Oxford University Press) $385 \mathrm{pp}$.

GARCÍA-Huidobro CORREA, Joaquín (1993): Razón práctica y derecho natural. El iusnaturalismo de Tomás de Aquino (Valparaíso, EDEVAL) 310 pp. 
García-Huidobro CorreA, Joaquín (2005): "Los conflictos de derechos", Revista Derecho y Humanidades, 11, pp. 61-68.

George, Robert P. (2009): Moral pública. Debates actuales (Santiago, Instituto de Estudios de la Sociedad) 208 pp.

Glendon, Mary Ann (1991): Rights Talk. The Impoverishment of Political Discourse (Nueva York, The Free Press) 218 pp.

GuZMán Brito, Alejandro: "Introducción”, en: Villey, Michel (1976), Estudios en torno a la noción de derecho subjetivo (Valparaíso, Ediciones Universitarias de Valparaíso) pp. 11-22.

HarT, H. L. A. (1961): The Concept of Law (Oxford, Oxford University Press, 1 a ed.) 263 pp.

HART, H. L. A. (1982): "Natural Rights: Bentham and John Stuart Mill”, en: HarT, H. L. A., Essays on Bentham. Jurisprudence and Political Theory (Oxford, Oxford University Press) pp. 79-104.

HERVADA, Javier (1993a): Introducción critica al derecho natural (Pamplona, Eunsa, 7a ed.) $195 \mathrm{pp}$.

HeRVADA, Javier (1993b): "Libertad de conciencia y error sobre la moralidad de una terapéutica”, en: HeRVADA, Javier, Escritos de derecho natural (Pamplona, Eunsa) pp. 565-626.

HobBes, Thomas (†1679): Leviathan (se cita por su división interna clásica).

Jolivet, Régis (1960): Tratado de filosofía. I Lógica y cosmología (Buenos Aires, Lohlé, 1960) 426 pp.

KaUfmann, Arthur (1999): Filosofía del derecho (Bogotá, Universidad Externado de Colombia) 655 pp.

Kelsen, Hans (1969): Teoría general del derecho y del Estado (México, Universidad Nacional Autónoma de México, $3^{a}$ ed.) 477 pp.

Kelsen, Hans (1994): Teoría general de las normas (México, Trillas) 392 pp.

MASSINI CORREAS, Carlos I. (1987): El derecho, los derechos humanos y el valor del derecho (Buenos Aires, Abeledo-Perrot) $234 \mathrm{pp}$.

MEgías, José Justo (2003): "El subjetivismo jurídico y el derecho subjetivo en los textos romanos”, en: CARPINTERO, F. et al.: El derecho subjetivo en su historia (Cádiz, Servicio de Publicaciones de la Universidad de Cádiz) pp. 17-34.

Millgram, Elijah (2001): "Practical Reasoning: The Current State of Play", en: MillGRAM, Elijah, Varieties of practical reasoning (Cambridge, Mass., MIT Press) pp. 126.

MirAnDA, Alejandro (2006): "La infalibilidad en el conocimiento de los primeros principios de la ley natural. Análisis a partir de los textos tomistas", en: LEGARRE, Santiago et al. (eds.), La lucha por el derecho natural. Actas de las Jornadas en Homenaje a John Finnis. A 25 años de la publicación de Natural Law and Natural Rights. Cuadernos de Extensión Jurídica (Universidad de los Andes) No 13, 2006, pp. 229-247.

Ruiz-Tagle Vial, Pablo (2006): "Entre el iusfundamentalismo y la democracia”, en Ruiz-Tagle Vial, Pablo y Cristi Becker, Renato (2006): La República en Chile. Teoría y práctica del Constitucionalismo Republicano (Santiago, LOM) pp. 255-275. 
Ruiz-Tagle Vial, Pablo y Cristi Becker, Renato (2006): “¿Qué es el Constitucionalismo?", en Ruiz-Tagle Vial, Pablo y Cristi BeCKer, Renato (2006): La República en Chile. Teoría y práctica del Constitucionalismo Republicano (Santiago, LOM) pp. 29-43.

SALDAÑA, Javier (2000): "Críticas en torno al derecho subjetivo como concepto de los derechos humanos", en: BEUCHOT, Mauricio y SALDAÑA, Javier, Derechos humanos y naturaleza humana (México, Universidad Nacional Autónoma de México) pp. 77104.

SERnA, Pedro y TOLLER, Fernando (2000): La interpretación constitucional de los derechos fundamentales. Una alternativa a los conflictos de derechos (Buenos Aires, La Ley) 171 pp.

Silva BASCUÑÁn, Alejandro (1997): Tratado de Derecho Constitucional (Santiago, Editorial Jurídica, $2^{\mathrm{a}}$ ed.) tomo I.

Silva Bascuñán, Alejandro (2006): Tratado de Derecho Constitucional (Santiago, Editorial Jurídica, $2^{\mathrm{a}}$ ed.) tomo XI.

Silva Bascuñán, Alejandro y Silva Gallinato, María Pía (2001): "Los derechos naturales ante la Constitución”, Revista Chilena de Derecho, 28, 2, pp. 249-252.

SQuella NARDuCCI, Agustín (2001): Filosofía del derecho (Santiago, Jurídica de Chile) 602 pp.

TiERNEY, Brian (1997): The Idea of Natural Rights. Studies on Natural Rights, Natural Law and Church Law 1150-1625 (Atlanta, Scholars Press) 380 pp.

Vigo, Alejandro G. (2006a): "Razón práctica y tiempo en Aristóteles. Futuro, incertidumbre y sentido", en: Vigo, A.: Estudios aristotélicos (Pamplona, Eunsa) pp. 279300.

Vigo, Alejandro G. (2006b): "La concepción aristotélica de la verdad práctica", en: Vigo, A.: Estudios aristotélicos (Pamplona, Eunsa) pp. 301-323.

VigO, Alejandro G. (2006c): "Incontinencia, carácter y razón”, en: VigO, A.: Estudios aristotélicos (Pamplona, Eunsa) pp. 325-362.

VIGO, Alejandro G. (2006d): "Verdad práctica y virtudes intelectuales", en: VIGO, A.: Estudios aristotélicos (Pamplona, Eunsa) pp. 363-403.

Vigo, Alejandro G. (2007): Aristóteles. Una introducción (Santiago, Instituto de Estudios de la Sociedad) 275 pp.

VILlEY, Michel (1976a): "Los orígenes de la noción de derecho subjetivo", en: VilleY, Michel, Estudios en torno a la noción de derecho subjetivo (Valparaíso, Ediciones Universitarias de Valparaíso) pp. 23-57.

Villey, Michel (1976b): "Crítica de los derechos del hombre", en: Villey, Michel, Estudios en torno a la noción de derecho subjetivo (Valparaíso, Ediciones Universitarias de Valparaíso) pp. 239-248.

Vivanco MartíneZ, Ángela (2006): Curso de Derecho Constitucional (Santiago, Ediciones Universidad Católica de Chile, $1^{\text {a }}$ ed.) tomo II.

Vivanco MartíneZ, Ángela (2007): Curso de Derecho Constitucional (Santiago, Ediciones Universidad Católica de Chile, 2a ed.) tomo I. 